\title{
Honokiol alleviates LPS-induced acute lung injury by inhibiting NLRP3 inflammasome-mediated pyroptosis via Nrf2 activation in vitro and in vivo
}

Yuhan Liu', Jiabin Zhou' ${ }^{2}$, Yingying Luo ${ }^{3}$, Jinxiao Li ${ }^{1}$, Luorui Shang ${ }^{1}$, Fangyuan Zhou ${ }^{1}$ and Shenglan Yang ${ }^{1^{*}}$ (1)

\begin{abstract}
Background: Honokiol (HKL) has been reported to ameliorate lipopolysaccharide (LPS)-induced acute lung injury (ALI). However, its potential mechanism of its protective effects remains unclear. In this study, the protective mechanism of HKL on LPS-induced ALI was explored in vivo and in vitro.

Methods: In vivo, the SD rats were intratracheally instilled with LPS (5 mg/kg) to establish an acute lung injury model and then treated with HKL $(1.25 / 2.5 / 5 \mathrm{mg} / \mathrm{kg})$ or ML385 $(30 \mathrm{mg} / \mathrm{kg})$ intraperitoneally. In vitro, the human bronchial epithelial cell line (BEAS-2B) was stimulated with LPS and ATP to induce pyroptosis and treated with HKL $(12.5 / 25 / 50 \mu M)$. Small interfering RNA (siRNA) technique was used to knockdown Nrf2 in BEAS-2B cells. The protein and mRNA expression levels of Nrf2, HO-1, NLRP3, ASC, CASP1, and GSDMD in cells and lung tissues were detected by western blot and real time-PCR. The expression levels of interleukin (IL)-1 $\beta, I L-18$, MPO, MDA, and SOD in bronchoalveolar lavage fluid (BALF) and supernatant were determined by ELISA. The degree of pathological injury of lung tissue was evaluated by H\&E staining.
\end{abstract}

Results: The results showed that HKL could alleviate oxidative stress and inflammatory responses by regulating the levels of MPO, MDA, SOD, IL-1 $\beta, I L-18$ in supernatant. And it could also inhibit the expression levels of NLRP3, ASC, CASP1, GSDMD via activation of Nrf2 in BEAS-2B cells. Further studies revealed that HKL could attenuate the pathological injury in LPS-induced ALI rats, and the molecular mechanism was consistent with the results in vitro.

Conclusions: Our study demonstrated that HKL could alleviate LPS-induced ALI by reducing the oxidative stress and inhibiting NLRP3 inflammasome-mediated pyroptosis, which was partly dependent on the Nrf2 activation.

Keywords: Acute lung injury, Honokiol, NLRP3 inflammasome, Pyroptosis, Nrf2, Lipopolysaccharide

\footnotetext{
*Correspondence: yangshenglan005@163.com

1 Department of Integrated Traditional Chinese and Western Medicine,

Union Hospital, Tongji Medical College, Huazhong University of Science and Technology, Wuhan 430022, China

Full list of author information is available at the end of the article
}

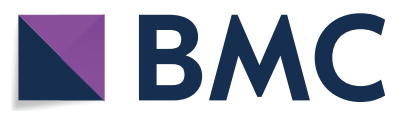

(c) The Author(s) 2021. Open Access This article is licensed under a Creative Commons Attribution 4.0 International License, which permits use, sharing, adaptation, distribution and reproduction in any medium or format, as long as you give appropriate credit to the original author(s) and the source, provide a link to the Creative Commons licence, and indicate if changes were made. The images or other third party material in this article are included in the article's Creative Commons licence, unless indicated otherwise in a credit line to the material. If material is not included in the article's Creative Commons licence and your intended use is not permitted by statutory regulation or exceeds the permitted use, you will need to obtain permission directly from the copyright holder. To view a copy of this licence, visit http://creativecommons.org/licenses/by/4.0/. The Creative Commons Public Domain Dedication waiver (http://creativeco mmons.org/publicdomain/zero/1.0/) applies to the data made available in this article, unless otherwise stated in a credit line to the data. 


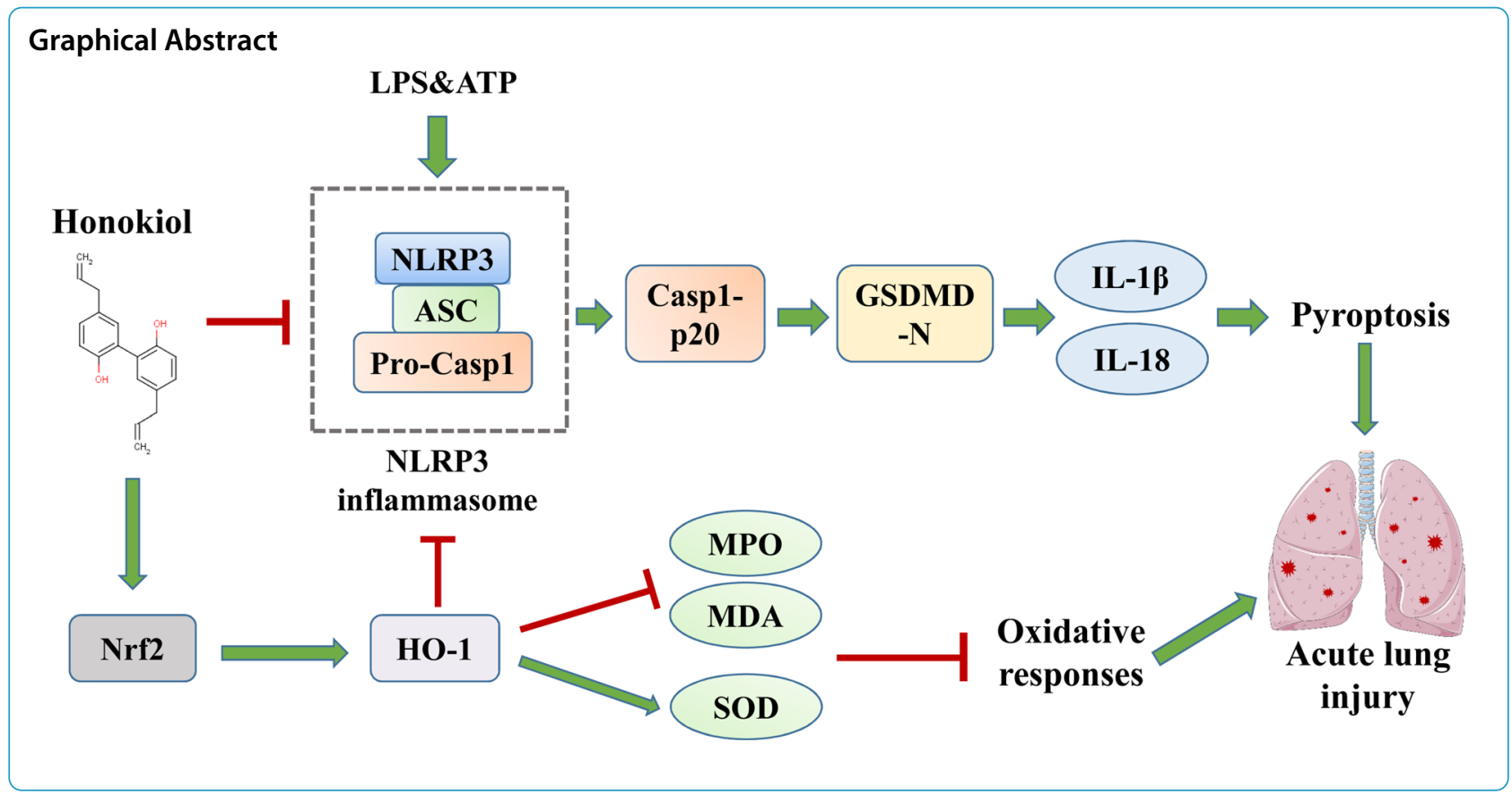

\section{Introduction}

Acute lung injury (ALI) and acute respiratory distress syndrome (ARDS) are mainly responsible for hypoxic respiratory failure in adults with high morbidity and mortality during hospitalization [1]. ALI is characterized by the diffused lung inflammation, damage of lung epithelial barrier, and pulmonary edema [2]. Increasing evidence depicts that airway epithelial cells are involved in the pathogenesis of ALI/ARDS. As the first line of lung defense against lung injury, airway epithelial cells can produce the epithelial-associated inflammatory factors and participate in promoting oxidative stress, local response, and tissue damage $[3,4]$. Therefore, airway epithelial cells are the potential therapeutic targets for preventing and treating ALI/ARDS.

The NOD-like receptor family pyrin domain containing 3 (NLRP3) inflammasome, is a vital component of innate immunity, comprising NLRP3, pro-caspase-1 (casp1), and apoptosis-associated speck-like protein containing a caspase-recruitment domain (ASC) [5]. The NLRP3 inflammasome activation requires two signals [6]: one being the transcriptional priming such as LPS and another one being ATP, nigericin, or monosodium urate (MSU) crystals. NLRP3 upon activation, processes the pro-casp1 into mature casp1, activating gasdermin D (GSDMD) that form holes in the cell membrane. As a result, the cells undergo pyroptosis releasing a large number of inflammatory factors such as IL- 18 and IL- $1 \beta$, and triggering severe inflammatory responses [7]. Recent evidence suggests that NLRP3 inflammasome-mediated pyroptosis in macrophages aggravates lung inflammation in LPS-induced ALI [8]. However, the role of pyroptosis in airway epithelial cells for the LPS-induced ALI remains unclear.

The transcription factor nuclear factor erythroid-2 related factor 2 (Nrf2) participates in regulating oxidative stress and inflammation $[9,10]$. Nrf2 under oxidative stress is translocated into the nucleus and binding with anti-oxidant response elements (AREs) in the promoter region of the cell-protective genes, such as heme oxygenase-1 (HO-1) and $\mathrm{NAD}(\mathrm{P}) \mathrm{H}$ quinone dehydrogenase 1 (NQO1) [11]. Recent studies have shown Nrf2 could inhibit the activation of the NLRP3 inflammasome [12]. Nevertheless, there have been no reports stating whether Nrf2 can affect the NLRP3 inflammasome-mediated pyroptosis in the airway epithelial cells.

Honokiol (HKL), a natural compound extracted from Magnolia officinalis, possesses anti-inflammatory and anti-oxidant properties [13, 14]. Related studies highlight that HKL can activate Nrf2 to improve oxidative stressinduced tissue damage [15] and antagonize NLRP3, thereby reducing the inflammatory response [16]. But, there is no clear indication of whether HKL can inhibit NLRP3 inflammasome-mediated pyroptosis in LPSinduced ALI.

This study hypothesized that HKL can suppress NLRP3 inflammasome-mediated pyroptosis and reduce the oxidative stress by activating Nrf2, thereby attenuating LPSinduced ALI. Based on this hypothesis, a series of studies were carried out. 


\section{Materials and methods Reagents}

Honokiol (Catalog No: B20498) was purchased from Yuanye Bio-Technology Co (Shanghai, China). LPS (Cata$\log$ No: Escherichia coli 055:B5) was purchased from Sigma (St. Louis, MO, USA). ATP (Catalog No: A9310) was purchased from Solarbio (Beijing, China). ChamQ ${ }^{\mathrm{TM}} \mathrm{SYBR}^{\circledR}$ qPCR Master Mix (Catalog No: Q311-02) and HiScript ${ }^{\circledR}$ II Q RT SuperMix for qPCR (Catalog No: R222-01) were obtained from Vazyme Biotechnology (Nanjing, China). Cell counting kit-8 kit was purchased from Dojindo (Kumamoto, Japan). Fetal bovine serum (FBS) was obtained from GIBCO (Grand Island, NY, USA) and Dulbecco's modified Eagle's medium/high glucose (DMEM, SH30022.01) and phosphate-buffered saline (PBS, SH30256.01) was purchased from HyClone (Logan, UT, United States). Hoechst 33342 (C1027) and Propidium Iodide (PI, ST511) staining solution were purchased from Beyotime Biotechnology (Shanghai, China). The IL-1 $\beta$ (Catalog No: E-EL-R0012c) ELISA kit and IL-18 (Catalog No.: SEA064Ra) for Rattus norvegicus were obtained from Elabscience Biotechnology (Wuhan, China) and USCN (Wuhan, China). The IL-1 $\beta$ (Catalog No: EK0392) ELISA kit and IL-18 (Catalog No: EK0864) for Homo sapiens were obtained from Boster Biological Technology (Wuhan, China). The myeloperoxidase (MPO) assay kit (Catalog No: A044-1-1), malondialdehyde (MDA) assay kit (Catalog No: A003-1-2) and Superoxide Dismutase (SOD) assay kit (Catalog No: A001-3-2) were obtained from the Jiancheng Bioengineering Institute of Nanjing (Nanjing, Jiangsu, China).

\section{Cell culture and treatment}

The human bronchial epithelial cell line (BEAS-2B) was purchased from the American Type Culture Collection (ATCC). BEAS-2B cells were cultured in the DMEM supplemented with $10 \% \mathrm{FBS}$ and $1 \%$ penicillin and streptomycin and the cells were maintained at $37{ }^{\circ} \mathrm{C}$ in a humidified atmosphere containing $5 \% \mathrm{CO}_{2}$. Cell experimental group I: BEAS-2B cells were divided into five groups: control group; LPS + ATP group; LPS + ATP + HKL groups $(12.5,25,50 \mu \mathrm{M})$. BEAS-2B cells in LPS + ATP + HKL groups were stimulated with LPS $(1 \mu \mathrm{g} / \mathrm{ml})$ for $4 \mathrm{~h}$ and ATP $(5 \mathrm{mM})$ for $30 \mathrm{~min}$ [17] following $20 \mathrm{~h}$ pretreatment with HKL. Cell experimental group II: BEAS-2B cells were divided into four groups: control group; TBHQ (tert-Butylhydroquinone, an Nrf2 agonist) group [18]; $\mathrm{LPS}+\mathrm{ATP}$ group; LPS + ATP + TBHQ $(20 \mu \mathrm{M})$ group. BEAS-2B cells in LPS + ATP + TBHQ group were stimulated with LPS $(1 \mu \mathrm{g} / \mathrm{ml})$ for $4 \mathrm{~h}$ and ATP $(5 \mathrm{mM})$ for $30 \mathrm{~min}$ following $20 \mathrm{~h}$ pretreatment with $\mathrm{TBHQ}$.

\section{Cell counting Kit-8 (CCK-8) assay}

To detect the cytotoxicity of HKL, $5 \times 10^{3}$ cells per well of plated BEAS-2B cells were treated with $100 \mu \mathrm{l}$ medium in 96-well plates overnight. Then, the culture medium was treated with HKL at varying concentrations $(6.25,12.5,25,50,100 \mu \mathrm{M})$. After $24 \mathrm{~h}$ or $48 \mathrm{~h}$, $10 \mu \mathrm{l}$ of the CCK-8 reagent were added to each well and incubated for $1.5 \mathrm{~h}$ away from light. The absorbance value of each well was measured on a microplate reader (Tecan Infinite F50, Switzerland) at $450 \mathrm{~nm}$.

\section{Small interfering (si) RNA transfection}

The specific human Nrf2 siRNA (5'-UCCCGUUUG UAGAUGACAA-3') was synthesized by Ruibo Biology (Guangzhou, China). The BEAS-2B cells were cultured in the 6-well plates and transfected with siRNAs plus transfection reagent riboFECT ${ }^{\mathrm{TM}} \mathrm{CP}$ (Guangzhou, China) according to the manufacturer's instructions. Six hour after transfection, the culture medium was replaced. Then, the cells continued to be cultivated till $48 \mathrm{~h}$. At $24 \mathrm{~h}$ before harvest, the cells were treated with HKL $(25 \mu \mathrm{M})$ for $20 \mathrm{~h}$, and then stimulated with LPS $(1 \mu \mathrm{g} / \mathrm{ml})$ for $4 \mathrm{~h}$ and ATP $(5 \mathrm{mM})$ for $30 \mathrm{~min}$.

\section{Animal experiments}

Male SD rats (SPF) (180-220 g) were purchased from Animal Experimental Center, Tongji Medical College, Huazhong University of Science and Technology (HUST) (Wuhan, China). These rats were maintained under a controlled environment at $23{ }^{\circ} \mathrm{C}$ under a $12 \mathrm{~h}$ dark/light cycle for 1 week. The rats were randomly divided into six groups $(\mathrm{n}=8)$ : control group, LPS group, LPS + HKL groups $(1.25,2.5,5 \mathrm{mg} / \mathrm{kg})$, LPS + HKL (2.5 mg/kg) + ML385 (30 mg/kg) group. Firstly, the rats were anesthetized by injecting sodium pentobarbital $(50 \mathrm{mg} / \mathrm{kg}$ ) intraperitoneally, followed by subsequent intratracheal instillation of $5 \mathrm{mg} /$ $\mathrm{kg}$ LPS in $50 \mu \mathrm{l}$ of sterile phosphate-buffered saline (PBS) [19], while the control group was administrated with an equal volume of PBS. Half an hour after LPS administration, the rats were injected intraperitoneally with HKL $(1.25,2.5,5 \mathrm{mg} / \mathrm{kg})$ [20] dissolved in DMSO, while the control group was treated with PBS alone. ML385 + HKL group was treated with ML385 (30 $\mathrm{mg} / \mathrm{kg}$, i.p.)[21] before LPS administration followed by HKL $(2.5 \mathrm{mg} / \mathrm{kg})$. After LPS intervention for $24 \mathrm{~h}$, the rats were euthanized by injecting $100 \mathrm{mg} / \mathrm{kg}$ sodium pentobarbital intraperitoneally. Subsequently, the bronchoalveolar lavage fluid (BALF) and lung tissues were collected. 


\section{Specimen collection}

After sacrificing the rats, the right lung was ligated, and the left lung was rinsed in $4.5 \mathrm{~mL}$ PBS $(1.5 \mathrm{~mL}$ per time) to collect the BALF. To calculate the lung wet/ dry ratio, the right upper lung was cut off and weighted, then was dried in an oven $\left(60{ }^{\circ} \mathrm{C}\right)$ for $72 \mathrm{~h}$ and weighed again. The remaining lung tissues were collected, one part was fixed in $4 \%$ paraformaldehyde for the hematoxylin and eosin (H\&E) staining, and the rest was frozen at $-80{ }^{\circ} \mathrm{C}$ for extracting the RNAs and proteins.

\section{Western blot}

The lung tissues and BEAS-2B cells were lysed with RIPA buffer with PMSF or phosphatase inhibitors. The protein concentration was detected by BCA assay kit. Equal volumes of the protein were added to each well and separated by $10 \%$ or $12 \%$ SDS-PAGE and were transferred to a PVDF $(0.45 \mathrm{~mm})$ membrane. The membranes were blocked in TBST containing Tween $20(0.1 \%)$ and fatfree milk (5\%) for $2 \mathrm{~h}$ at room temperature. The membranes were then rinsed with TBST buffer three times for $10 \mathrm{~min}$ and incubated with anti-NLRP3 (ABclonel, A5652, 1:500), anti-ASC (ABclonel, A1170, 1:800), anti-CASP1 (ABclonel, A0964, 1:750), anti-GSDMD (ABclonel, A18281, 1:800), anti-Nrf2 (Proteintech, 16,396-1-AP, 1:1000), anti-HO-1 (Proteintech, 10701-1AP, 1:3000), anti-Histone H3 (Proteintech, 17168-1-AP, 1:3000), anti-GAPDH (BOSTER, BM3874, 1:1000) antibodies overnight at $4{ }^{\circ} \mathrm{C}$. After washing with TBST three times for $5 \mathrm{~min}$, these membranes were then incubated in the rabbit HRP-conjugated secondary antibody (1:5000) at room temperature for $1 \mathrm{~h}$. The bands were developed using enhanced chemiluminescence kit (NCM Biotech,
P10300) and the signals were detected by a UVP BioSpectrum Imaging System (BioSpectrum600). The intensity of all bands was quantified using ImageJ software.

Real-time polymerase chain reaction analysis (RT-PCR)

The total RNA of BEAS-2B cells and lung tissues were isolated through RNA isolation Total RNA Extraction Reagent (No: R401-01) (Vazyme, Nanjing) and then reverse-transcribed into cDNA with $\mathrm{HiScript}^{\circledR}$ II Q RT SuperMix according to the instructions. The reaction conditions were designed according to the instructions (ChamQTM SYBR ${ }^{\circledR}$ qPCR Master Mix). Thermal cycling conditions were $30 \mathrm{~s}$ at $95{ }^{\circ} \mathrm{C}, 5 \mathrm{~s}$ at $95{ }^{\circ} \mathrm{C}$, and $30 \mathrm{~s}$ at $60{ }^{\circ} \mathrm{C}$, followed by 40 cycles, and at $95{ }^{\circ} \mathrm{C}$ for $15 \mathrm{~s}, 60{ }^{\circ} \mathrm{C}$ for $1 \mathrm{~min}$, and $95{ }^{\circ} \mathrm{C}$ for $15 \mathrm{~s}$ in StepOne Plus (Applied Biosystems).The primers were synthesized by Tsingke Biology (Wuhan, China). The sequences of all primers are listed in Table 1.

\section{Hoechst33342/Propidium lodide (PI) staining}

The cells were stained using Hoechst 33342 and PI staining solution at $4{ }^{\circ} \mathrm{C}$ for $20 \mathrm{~min}$. After staining, the cells were rinsed once with PBS and observed under a fluorescence microscope (Olympus, Japan). The rate of PI-positive cells was analyzed using ImageJ software.

\section{Lactate dehydrogenase (LDH) release assay}

The release of LDH in the cell supernatant was detected by the LDH kit (Jiancheng, Nanjing, China) according to the manufacturer's instructions. The optical density (OD) value was measured at $490 \mathrm{~nm}$ in a microplate reader (Tecan Infinite F50, Switzerland).

Table 1 Sequences of primers for RT-PCR

\begin{tabular}{|c|c|c|c|}
\hline Gene & Primer sequence & Rat $\left(5^{\prime}\right.$ to $\left.3^{\prime}\right)$ & Human $\left(5^{\prime}\right.$ to $\left.3^{\prime}\right)$ \\
\hline \multirow[t]{2}{*}{ NLRP3 } & Forward primer & TCTTTGCGGCTATGTACTATCT & GGACTATTTCCCCAAGATTG \\
\hline & Reverse primer & TTCTAATAGGACCTTCACGT & ACTCCACCCGATGACAGTT \\
\hline \multirow[t]{2}{*}{ ASC } & Forward primer & ATCCTGGACGCTCTTGAAAACTT & CTCACCGCTAACGTGCTGC \\
\hline & Reverse primer & GCTCCTGTATGCCCATGTCTCTA & CTTGGCTGCCGACTGAGGA \\
\hline \multirow[t]{2}{*}{ CASP-1 } & Forward primer & CGGGCAAGCCAGATGTTTAT & GGGCTCTGTTTTTATTGGAA \\
\hline & Reverse primer & AACCACTCGGTCCAGGAAATG & ATCTGGCTGCTCAAATGAA \\
\hline \multirow[t]{2}{*}{ GSDMD } & Forward primer & CCAACATCTCAGGGCCCCAT & GGACAGGCAAAGATCGCAG \\
\hline & Reverse primer & TGGCAAGTTTCTGCCCTGGA & CACTCAGCGAGTACACATTCATT \\
\hline \multirow[t]{2}{*}{ Nrf2 } & Forward primer & GGACCTAAAGCACAGCCAAC & TCCAGTCAGAAACCAGTGGAT \\
\hline & Reverse primer & ATCTCTGGTCTGCTGCAGAG & GAATGTCTGCGCCAAAAGCTG \\
\hline \multirow[t]{2}{*}{$\mathrm{HO}-1$} & Forward primer & CTTACACACCAGCCACACAG & AAGACTGCGTTCCTGCTCAAC \\
\hline & Reverse primer & ACTGAGTGTGAGGACCCATC & AAAGCCCTACAGCAACTGTCG \\
\hline \multirow[t]{2}{*}{ GAPDH } & Forward primer & GACATGCCGCCTGGAGAAAC & ACAACTTTGGTATCGTGGAAGG \\
\hline & Reverse primer & AGCCCAGGATGCCCTTTAGT & GCCATCACGCCACAGTTTC \\
\hline
\end{tabular}




\section{Immunofluorescence (IF) staining}

BEAS-2B cells were seeded into a 24-well culture plate plated with cell climbing slices for IF at a density of $3 \times 10^{4}$ cells/well for $12 \mathrm{~h}$, then stimulated and treated as described above in the section entitled Cell culture and treatment. The cell climbing slices were washed and fixed with $4 \%$ paraformaldehyde for $20 \mathrm{~min}$ at room temperature, washed again and blocked with normal goat serum for $30 \mathrm{~min}$ at room temperature, incubated with primary antibody (GSDMD, 1:80, ABclonal, A18281) at $4{ }^{\circ} \mathrm{C}$ overnight, then, washed again, incubated with DyLight 488 affinipure goat anti-rabbit IgG at $37^{\circ} \mathrm{C}$ in the dark for $1 \mathrm{~h}$. Eventually, the slices were washed, protected from light and stained with DAPI for $10 \mathrm{~min}$ at room temperature, washed, sealed with anti-fluorescence quenching sealing tablets and observed under fluorescence microscope (IX73, Olympus, Tokyo, Japan). The immunofluorescence intensity of GSDMD was quantified using ImageJ software.

\section{Measurement of MPO, MDA and SOD}

The activity of MPO and levels of MDA and SOD in cell supernatant and BALF were determined using the MPO, MDA and SOD assay kits (Nanjing Jiancheng Bioengineering Institute, China) according to the manufacturer's instructions. The optical density (OD) value of MPO, MDA and SOD was measured at $460 \mathrm{~nm}, 532 \mathrm{~nm}$ and $450 \mathrm{~nm}$ in a microplate reader (Tecan Infinite F50, Switzerland).

\section{Histopathological analysis}

The lung tissues were soaked in $10 \%$ neutral buffered formalin for $24 \mathrm{~h}$ and then the samples were dehydrated with graded alcohol dilutions. Subsequently, the tissues were embedded in a wax block and sliced into paraffin sections, which were stained with hematoxylin-eosin $(H \& E)$, and pathological changes of the lung tissues were observed using a light microscope (Olympus BX53 biological microscope). The lung injury was assessed independently by two blinded pathologists according to following items: neutrophils infiltration to the airspace or alveolar space, hyaline membranes formation, alveolar septal thickening, pulmonary hemorrhage [22]. The scores were as follows: no injury with a score of 0 ; mild to moderate injury with a score of $0.1-2.5$; and severe injury with a score of 2.6-4.0 [23].

\section{Immunohistochemical (IHC) analysis}

The lung tissues were fixed and embedded in a wax block, then sliced into $5-\mu \mathrm{m}$ sections. The sections were dewaxed with xylene, rehydrated by fractional ethanol, repaired by antigen, and blocked with goat serum, then incubated with the primary antibody (GSDMD, 1:100,
ABclonal, A18281) at $4{ }^{\circ} \mathrm{C}$ overnight, washed and incubated with secondary antibody at room temperature for 20 min, washed again and stained with DAB solution at room temperature for $6 \mathrm{~min}$. Finally, the sections were washed, counterstained, dehydrated, transparentized, sealed and visualized with a light microscope (Olympus BX53 biological microscope). Image-Pro Plus 6.0 software was used to measure and analyze the intensity of IHC staining images.

\section{Enzyme-Linked immunosorbent assay (ELISA)}

The levels of IL- $1 \beta$ and IL-18 in the cell supernatant and BALF were detected by ELISA. According to the manufacturer's instructions, the working reagents were added to each well in sequence, and the optical density (OD) value was detected at $450 \mathrm{~nm}$ in a microplate reader (Tecan Infinite F50, Switzerland).

\section{Statistical analysis}

All statistical data were analyzed using GraphPad Prism software v8.0. One-way ANOVA and Student's $t$-test were used to determine the significance of the statistical results. Data are expressed as the mean \pm standard deviation (SD). $P<0.05$ was considered to be statistically significant.

\section{Results}

\section{Cytotoxicity of honokiol in BEAS-2B cells}

As shown in Fig. 1A, the molecular formula of honokiol (HKL) is $\mathrm{C}_{18} \mathrm{H}_{18} \mathrm{O}_{2}$. To assess the cytotoxicity of HKL in BEAS-2B cells, the cells were treated with HKL (6.25, $12.5,25,50,100 \mu \mathrm{M})$ for 24 or $48 \mathrm{~h}$, then, cell viability was detected by Cell Counting Kit-8 (CCK8) assay. The results showed that the cell viability decreased to 78 and $72 \%$ after treatment with $100 \mu \mathrm{M}$ HKL for 24 or $48 \mathrm{~h}$ and maintained above $80 \%$ after treatment with $50 \mu \mathrm{M}$ HKL for 24 or $48 \mathrm{~h}$ (Fig. 1B). Therefore, $50 \mu \mathrm{M}$ was determined as the highest concentration for subsequent experiments.

\section{Honokiol inhibits NLRP3 inflammasome-mediated pyroptosis in LPS and ATP- stimulated BEAS-2B cells}

To explore the effect of HKL on pyroptosis, the BEAS-2B cells were treated with LPS and ATP, and then the level of pyroptosis was determined by calculating the ratio of PI-positive cells and the level of LDH released from the cell supernatant. Results showed that HKL significantly reduced the rate of PI-positive cells and the release of LDH in supernatant (Fig. 1C-E). Meanwhile, the markers of NLRP3 inflammasome activation, such as ASC, Caspase-1 p20 subunit (CASP1-P20), the $\mathrm{N}$-terminal fragment generated from the cleavage of pyroptosis execution protein-GSDMD (GSDMD-N), IL-18 and IL-1 $\beta$ were detected. Additionally, HKL decreased the NLRP3, ASC, 
A
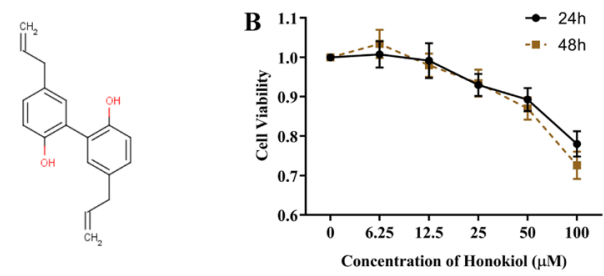

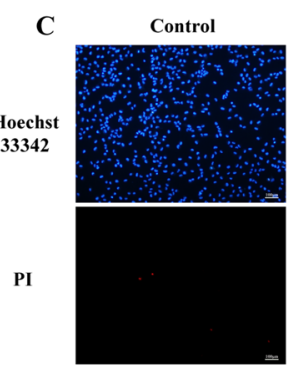

D
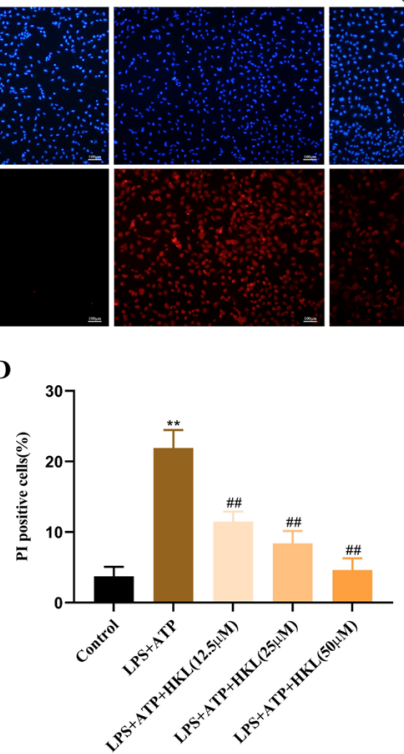

LPS+ATP+HKL

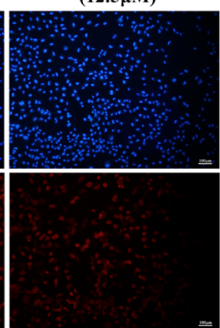

$\mathbf{E}$

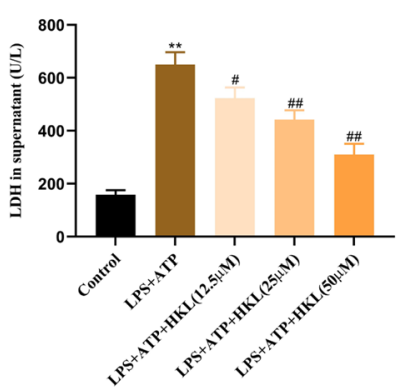

LPS+ATP+HKL

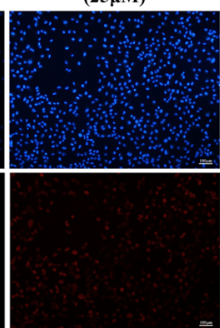

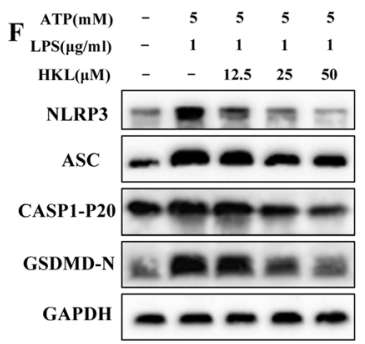

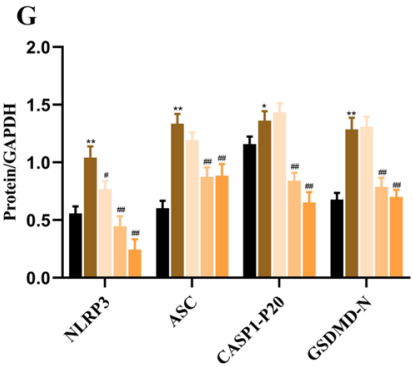

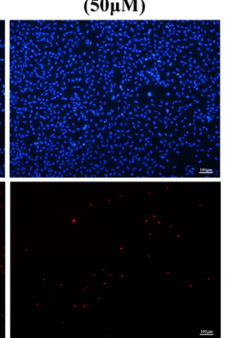

H

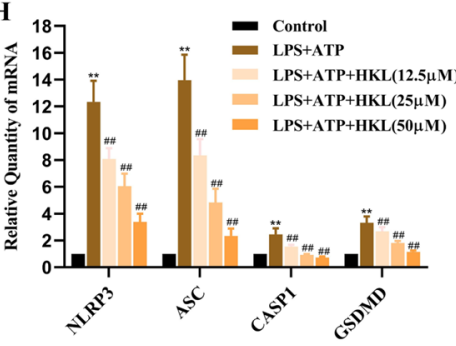

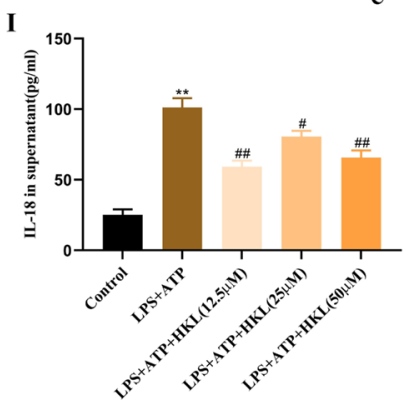

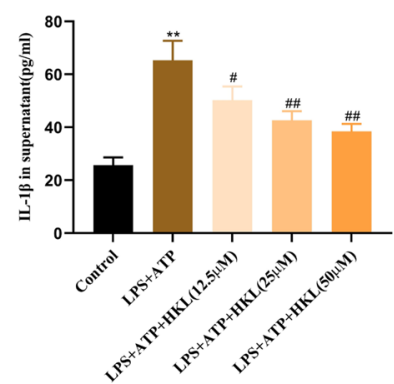

Fig. 1 Honokiol suppresses NLRP3 inflammasome-mediated pyroptosis in BEAS-2B cells. A The molecular formula of honokiol (HKL). B BEAS-2B cells were treated with $\operatorname{HKL}(0,6.25,12.5,25,50,100 \mu \mathrm{M})$ for 24 or $48 \mathrm{~h}$, and then cytotoxicity was detected by CCK-8 assay. BEAS-2B cells were divided into five groups: control group; LPS + ATP group; LPS + ATP + HKL groups (12.5, 25, $50 \mu \mathrm{M})$. BEAS-2B cells in LPS + ATP + HKL groups were stimulated with LPS $(1 \mathrm{\mu g} / \mathrm{ml})$ for $4 \mathrm{~h}$ and ATP $(5 \mathrm{mM})$ for 30 min following $20 \mathrm{~h}$ pretreatment with HKL (C-D) using Hoechst 33,342 (blue)/PI (red) double-fluorescent staining $(100 \times)$. Nucleus was stained using Hoechst33342. Pl staining indicated the loss of plasma membrane integrity. The rate of Pl-positive cells was calculated using ImageJ software. $\mathbf{E} L D H$ release in supernatant. F, G The protein expression of NLRP3, ASC, CASP1-P20, GSDMD-N were detected by western blot. H The mRNA expression of NLRP3, ASC, CASP1, GSDMD were detected by RT-PCR. I, J The production of IL-18 and IL-1 $\beta$ in supernatant were measured by ELISA. Values are expressed as the mean \pm SD of three independent experiments. ${ }^{*} P<0.05$, ${ }^{* *} P<0.01$ compared with the control group, ${ }^{\#} P<0.05,{ }^{\# \#} P<0.01$ compared with LPS + ATP group 
CASP1-P20 and GSDMD-N protein and NLRP3, ASC, CASP1 and GSDMD mRNA levels, and suppressed the production of Interleukin-18 (IL-18) and Interleukin-1 $\beta$ (IL-1 $\beta$ ) in supernatant compared with LPS + ATP group (Fig. 1F-J). Above results suggest that HKL can prevent the pyroptosis via inhibiting NLRP3 inflammasome activation and GSDMD cleavage in BEAS-2B cells induced by LPS and ATP.

\section{Honokiol activates Nrf2 and improves the oxidative stress in LPS and ATP-stimulated BEAS-2B cells}

HKL was recently reported to possess strong anti-oxidative activity [24], however, the anti-oxidant effect of HKL in lung epithelial cells has not been studied. Thus, we explored the anti-oxidant effect and potential mechanism of HKL on BEAS-2B cells after LPS and ATP stimulation. Firstly, we evaluated the effect of HKL on oxidative stress markers such as MDA, MPO, and SOD, and found that HKL significantly reduced MPO and MDA levels, and increased SOD levels in BEAS-2B cells (Fig. 2D-F). To explore the anti-oxidative mechanism of HKL in BEAS2B cells, we assessed the effect of HKL on Nrf2. Nrf2, as a transcription factor, can regulate oxidative stress [25].
The results showed that HKL could promote Nrf2 translocation into the nucleus, and increase the protein and mRNA expression of total Nrf2 and HO-1 (Fig. 2A-C). These results altogether indicated that HKL could reduce the oxidative stress and activate Nrf2.

\section{Honokiol exerts its anti-oxidative effect in LPS and ATP-stimulated BEAS-2B cells via activation of Nrf2}

To verify whether the anti-oxidant effect of HKL in LPS and ATP-stimulated BEAS-2B cells is related to Nrf2, Nrf2 was knocked down by the siRNA technology (Fig. 3A) and found that the regulation of HKL on Nrf2, HO-1, MPO, MDA and SOD in LPS and ATP-stimulated BEAS-2B cells were reversed (Fig. 3B-G), which suggested that the anti-oxidative property of HKL in LPS and ATP-stimulated BEAS-2B cells was at least partially dependent on the activation of Nrf2.

\section{Activation of Nrf2 inhibits NLRP3 inflammasome-mediated pyroptosis in BEAS-2B cells}

Nrf2 has been recently shown to be the key factor in the activation of the NLRP3 inflammasome [26]. However, it is not clear whether NRF2 can regulate NLRP3

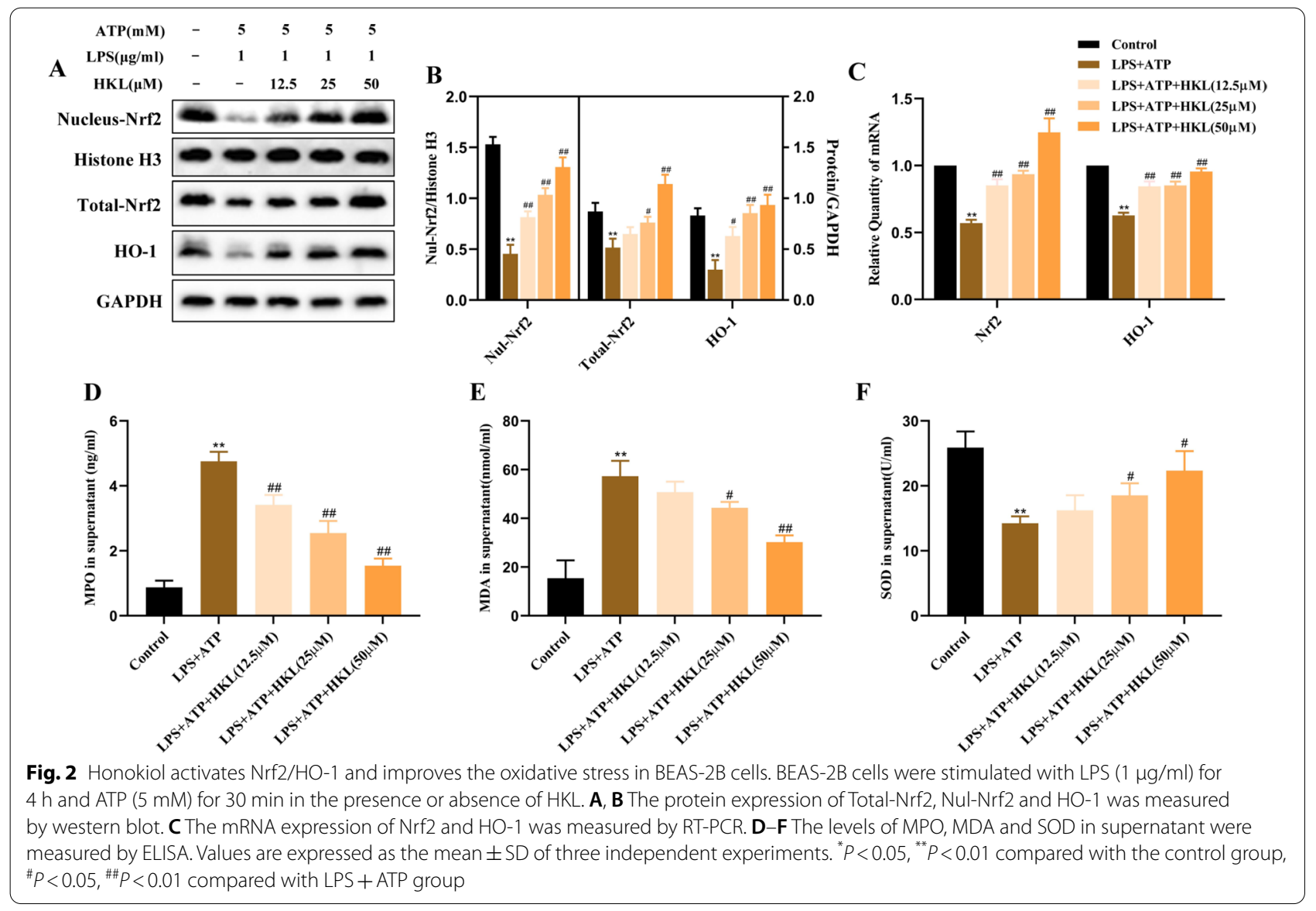




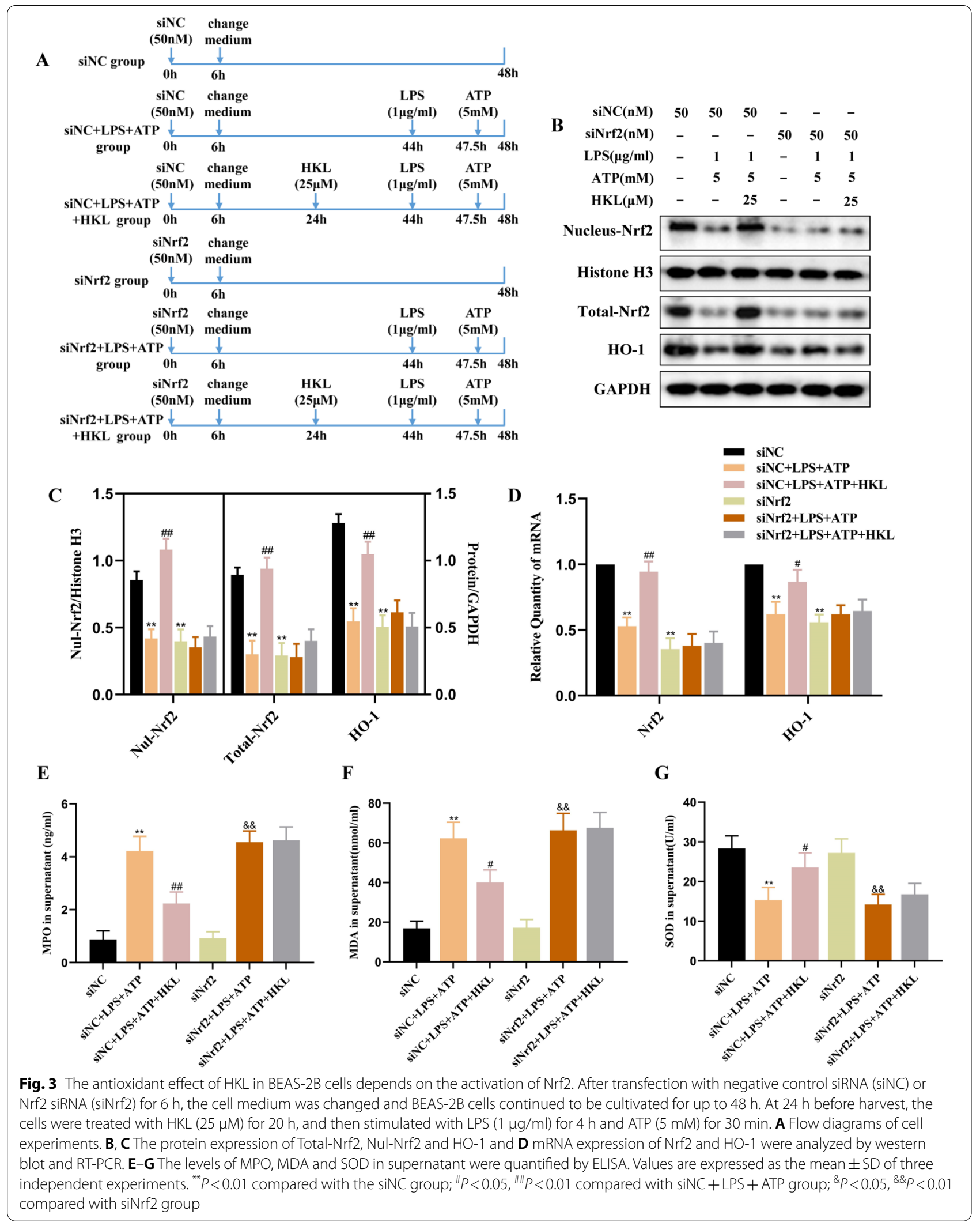


inflammasome-mediated pyroptosis in BEAS-2B cells stimulated with LPS and ATP. So we pretreated BEAS$2 B$ cells with TBHQ (an Nrf2 agonist) to observe whether it affects pyroptosis. As shown in Fig. 4A-J, the rate of PI-positive cells, release of LDH, protein expression of NLRP3, ASC, CASP1-P20, GSDMD-N, mRNA expression of NLRP3, ASC, CASP1, GSDMD, production of IL-18 and IL- $1 \beta$ in THBQ group were totally decreased than those in the control groups. Meanwhile, the levels of these pyroptosis-related indexes in TBHQ pretreatment group were also significantly lower than those in LPS + ATP group. The above results showed that activation of Nrf2 could inhibit the NLRP3 inflammasomemediated pyroptosis in BEAS-2B cells stimulated with LPS and ATP.

\section{Honokiol suppresses NLRP3 inflammasome-mediated pyroptosis in LPS and ATP stimulated-BEAS-2B cells via activation of Nrf2}

To observe whether the inhibitory effect of HKL on NLRP3 inflammasome-mediated pyroptosis was linked to the activation of Nrf2, we knocked down Nrf2 in BEAS-2B cells using siRNA technology. The results suggested that after siRNA-NC transfection, HKL could still inhibit the protein expression of NLRP3, ASC, CASP1-P20, GSDMD-N protein and mRNA expression of NLRP3, ASC, CASP1, GSDMD, decrease the rate of PI-positive cells positive and the release of IL18, IL-1 $\beta$ and LDH in cell supernatant (Fig. 5A-H). However, after siRNA-Nrf2 administration, the inhibition of HKL on NLRP3 inflammasome-mediated pyroptosis was significantly reversed (Fig. 5A-H). Thus, the inhibitory effect of HKL on the NLRP3 inflammasome-mediated pyroptosis was discovered to be partially dependent on the activation of Nrf2.

\section{Honokiol attenuates LPS-induced ALI in rats}

To determine the protective effect of HKL on LPSinduced ALI rats, the pathological changes of rat lung tissues were assessed by H\&E staining. As shown in Fig. 6B, C, The ALI scores of LPS group were significantly higher than the control group and the pathological changes were characterized by increased accumulation of inflammatory cells, alveolar hemorrhage and pulmonary interstitial edema. However, the degree of pathological injury of lung tissues and the ALI scores in LPS + HKL groups were significantly improved and decreased. At the same time, the lung wet/dry (W/D) weight ratio was detected to evaluate the edema of rat lung tissues. As shown in Fig. $6 \mathrm{D}$, the lung W/D weight ratio of the rats in the LPS group was significantly increased compared with the control group, while HKL treatment could significantly reduce the ratio. The results suggested that HKL could effectively attenuate LPS-induced ALI in rats. Interestingly, it was found that pretreatment with ML385 could significantly weaken the protective effect of HKL on LPSinduced ALI, which suggested that the protective effect of HKL on LPS-induced ALI was at least partially related to the activation of $\mathrm{Nrf} 2$.

\section{Honokiol exerts an anti-oxidative effect to attenuate LPS-induced ALI via activation of Nrf2}

To investigate whether the protective mechanism of HKL against LPS-induced ALI is related to its anti-oxidant activity, the activities of the oxidative stress markers, such as MPO, MDA, SOD were determined, and the Nrf2 and HO-1 expression levels were also detected. It was found that LPS administration could significantly increase the activities of MPO and MDA, and inhibit the level of SOD in BALF, but, all of which could be reversed by pretreatment of HKL (Fig. 7G-I). Additionally, we observed that HKL increased the protein and mRNA level of Nrf2 and $\mathrm{HO}-1$ in rat lung tissues (Fig. $7 \mathrm{~A}-\mathrm{C}$ ). To further verify whether the anti-oxidative protection of HKL on LPSinduced ALI depended on the activation of Nrf2, the rats were pretreated with ML385, an inhibitor of Nrf2. Interestingly, the regulatory effect of $\mathrm{HKL}$ on Nrf2, HO-1, and oxidative stress markers was significantly blocked by ML385 (Fig. 7D-I). Accordingly, we proposed that the anti-oxidative protection of HKL on LPS-induced ALI was dependent on $\mathrm{Nrf} 2$ activation.

\section{Honokiol inhibits NLRP3 inflammasome-mediated pyroptosis in LPS induced-ALI rats via activation of Nrf2}

To investigate the anti-inflammatory and protective mechanisms of HKL on LPS-induced ALI, we observed whether HKL could inhibit NLRP3 inflammasome-mediated pyroptosis in vivo.

The results indicated that after LPS stimulation, the protein levels of NLRP3, ASC, CASP1-P20 and GSDMD$\mathrm{N}$ and mRNA levels of NLRP3, ASC, CASP1 and GSDMD in lung tissues and the release of LDH, IL-18, IL-1 $\beta$ in BALF were significantly increased (Fig. 8A-C, G-K). Consistent with the results in vitro, HKL was found to suppress the activation of NLRP3 inflammasome and reduce the release of $\mathrm{LDH}$, IL-18 and IL- $1 \beta$ (Fig. 8A-C, G-K). To verify whether the inhibitory effect of HKL on NLRP3 inflammasome-mediated pyroptosis in vivo is related to the activation of $\mathrm{Nrf} 2$, the rats were pretreated with ML385, an Nrf2 inhibitor. After the administration of ML385, HKL could neither downregulate the NLRP3, ASC, CASP1-P20, GSDMD-N protein levels and NLRP3, ASC, CASP1, GSDMD mRNA levels of in the lung tissues, nor reduce the release of IL18, IL1 $\beta$ and LDH in the BALF (Fig. 8D-K). To summarize the above results, HKL was suggested to exert its anti-inflammatory effect to 

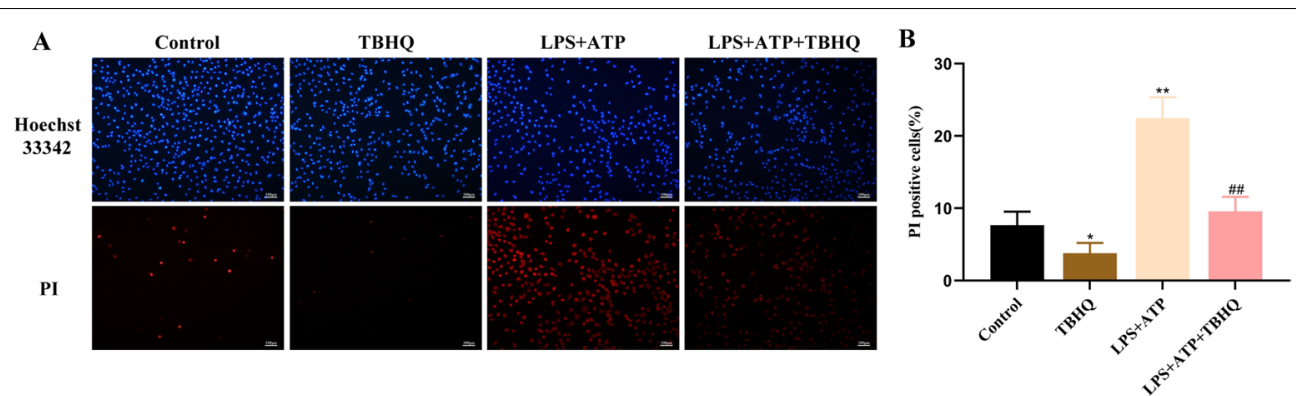
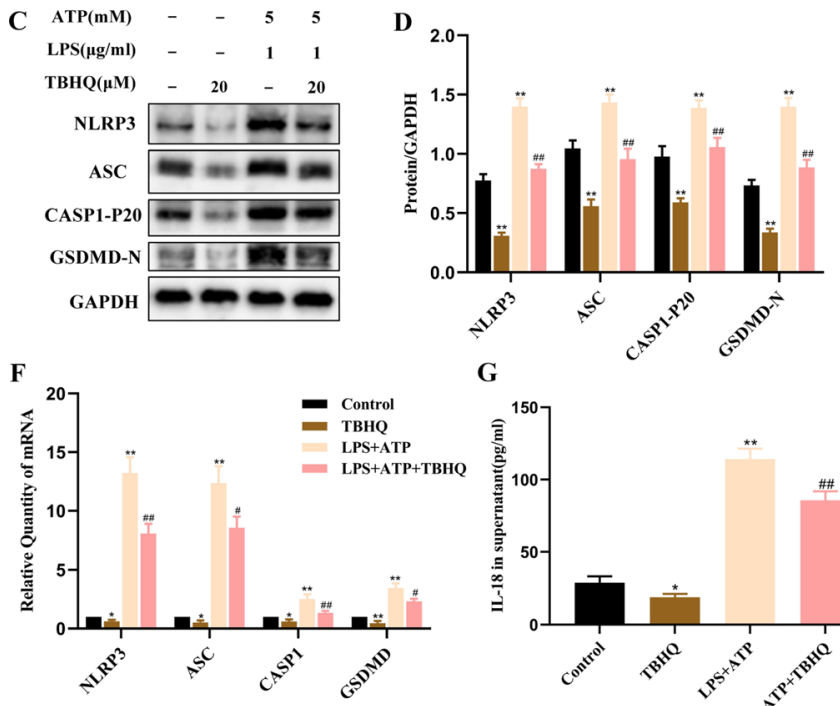

G

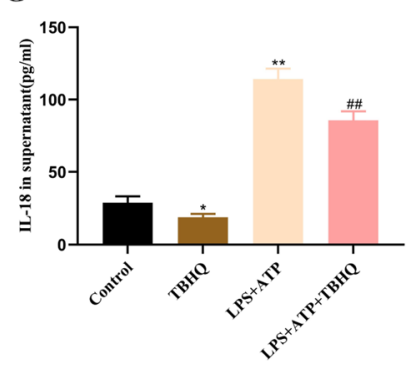

E
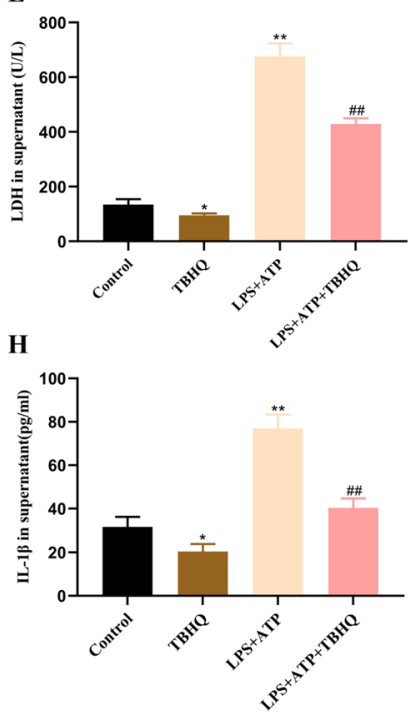
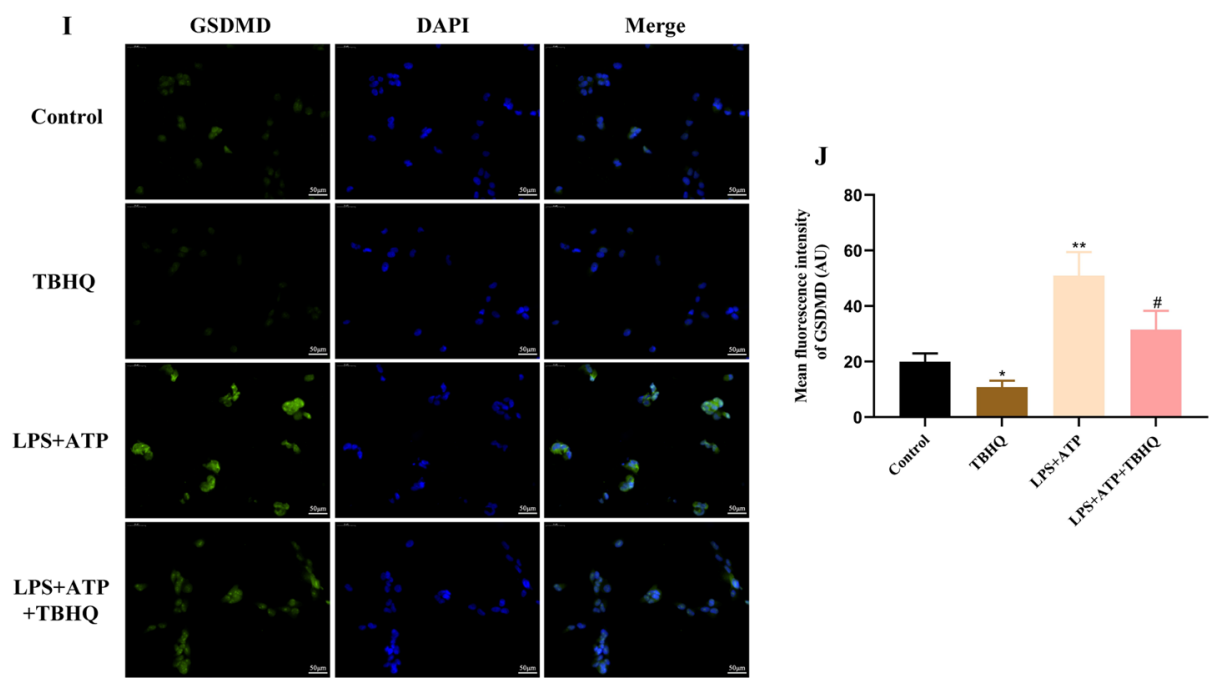

Fig. 4 Activation of Nrf2 inhibits NLRP3 inflammasome-mediated pyroptosis in BEAS-2B cells. BEAS-2B cells were divided into four groups: control group; TBHQ group; LPS + ATP group; LPS + ATP + TBHQ $(20 \mu \mathrm{M})$ group. BEAS-2B cells in LPS + ATP + TBHQ group were stimulated with LPS (1 $\mu$ g/ $\mathrm{ml}$ ) for $4 \mathrm{~h}$ and ATP $(5 \mathrm{mM})$ for $30 \mathrm{~min}$ following $20 \mathrm{~h}$ pretreatment with TBHQ. A, B Hoechst 33,342 (blue)/PI (red) double-fluorescent staining $(100 \times)$ and the rate of PI-positive cell. C, D The protein expression of NLRP3, ASC, CASP1-P20, GSDMD-N were detected by western blot. E LDH release in supernatant. $\mathbf{F}$ The mRNA expression of NLRP3, ASC, CASP1, GSDMD were detected by RT-PCR. G, H The production of IL-18 and IL-1 $\beta$ in supernatant were measured by ELISA. I Immunofluorescence staining of GSDMD (original magnification $400 \times$ ). Merged images of DAPI for nucleus (blue) and GSDMD immunofluorescence (green). J The mean fluorescence intensity (MFI) was quantified using Image software. MFI= Integrated Density/Area. Values are expressed as the mean \pm SD of three independent experiments. ${ }^{*} \mathrm{P}<0.05,{ }^{* *} \mathrm{P}<0.01 \mathrm{compared}$ with the control group, 


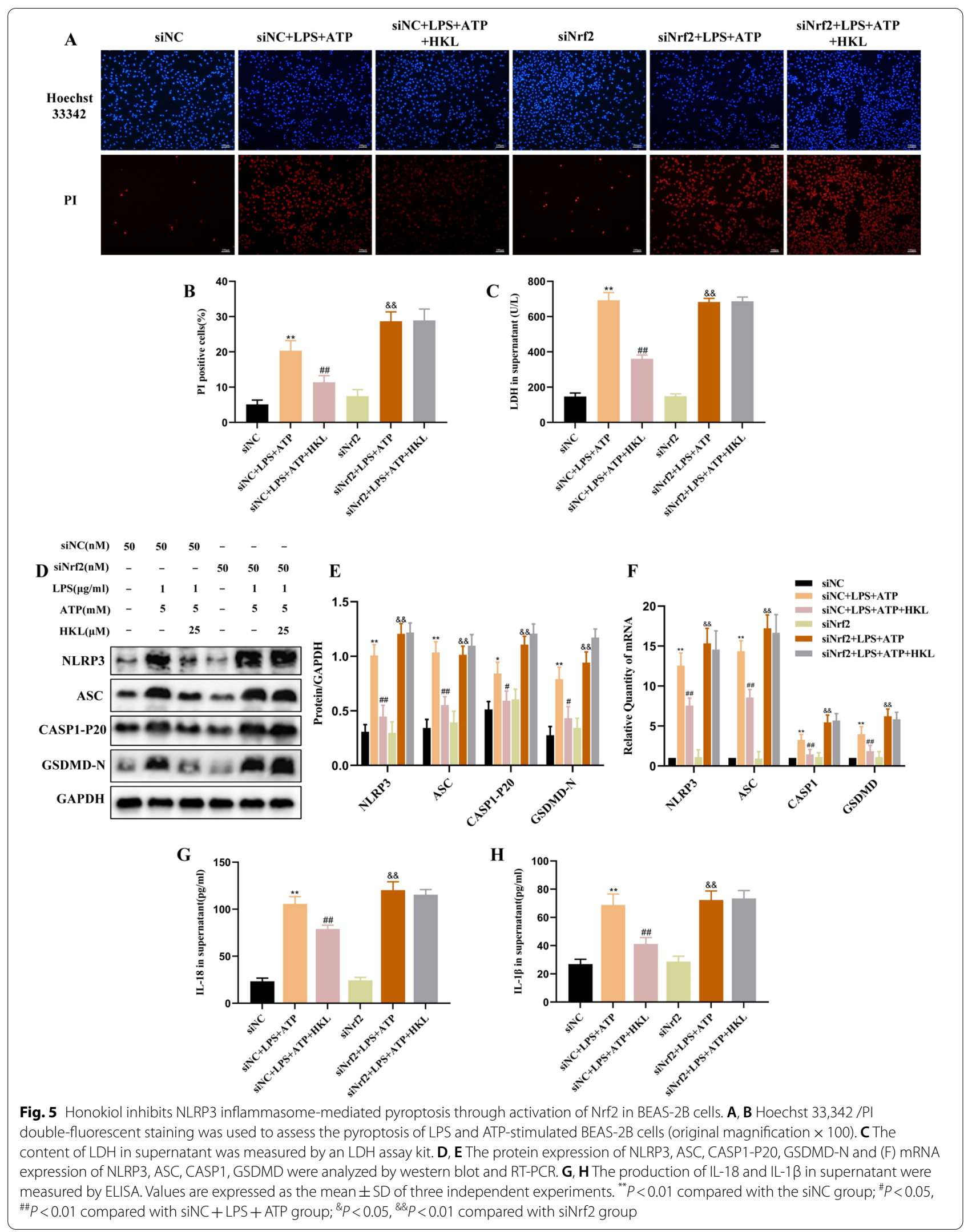


A

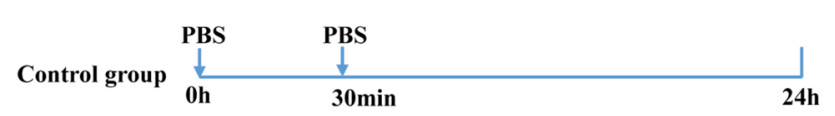

LPS

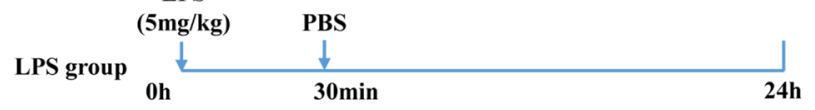

HKL

$(5 \mathrm{mg} / \mathrm{kg})(1.25 / 2.5 / 5 \mathrm{mg} / \mathrm{kg})$

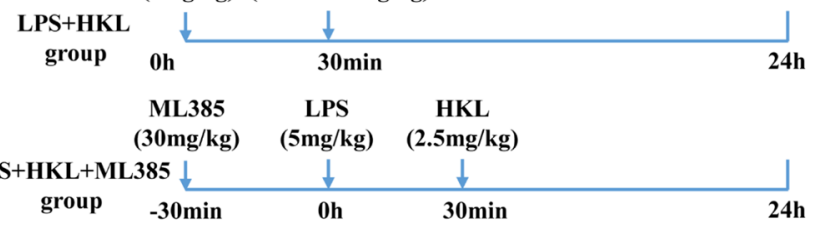

B

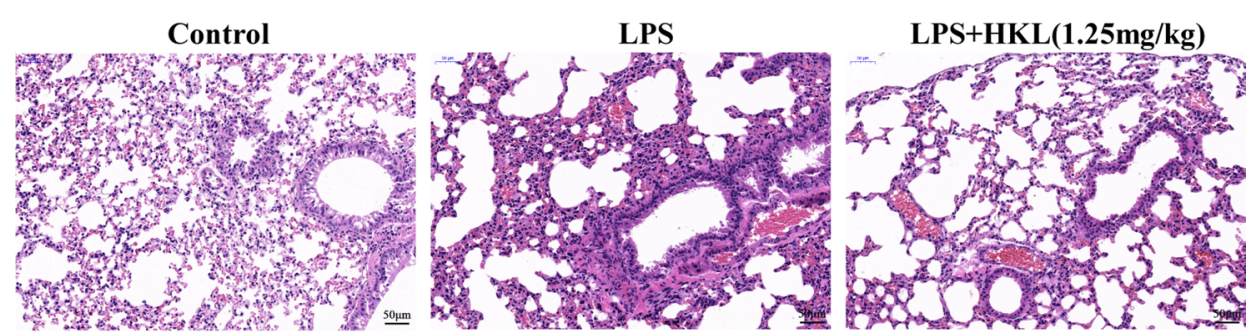

LPS+HKL $(2.5 \mathrm{mg} / \mathrm{kg})$

LPS+HKL $(5 \mathrm{mg} / \mathrm{kg})$

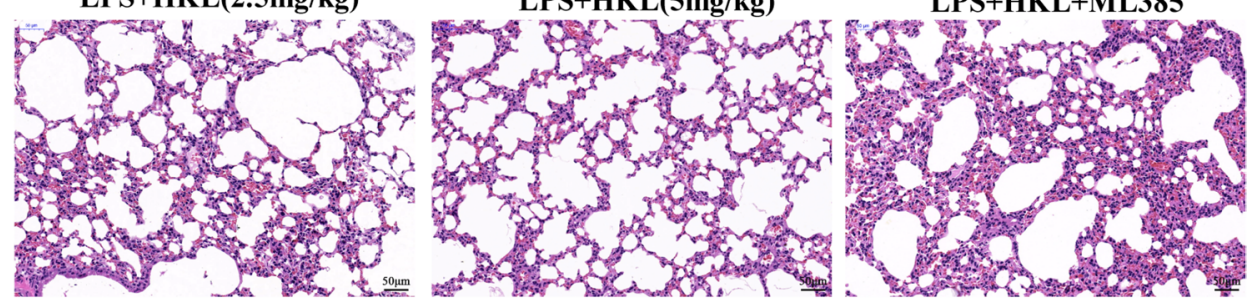

C

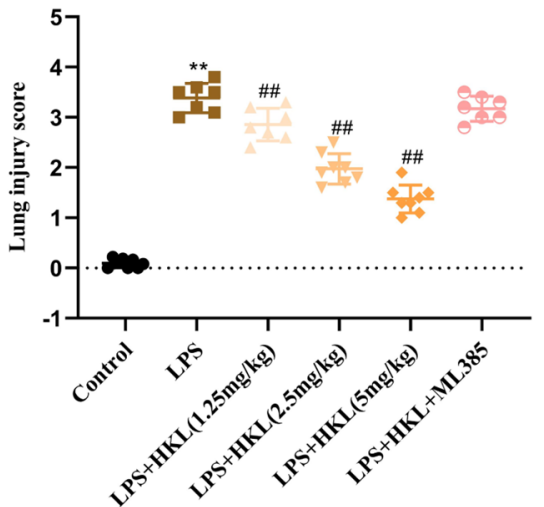

D

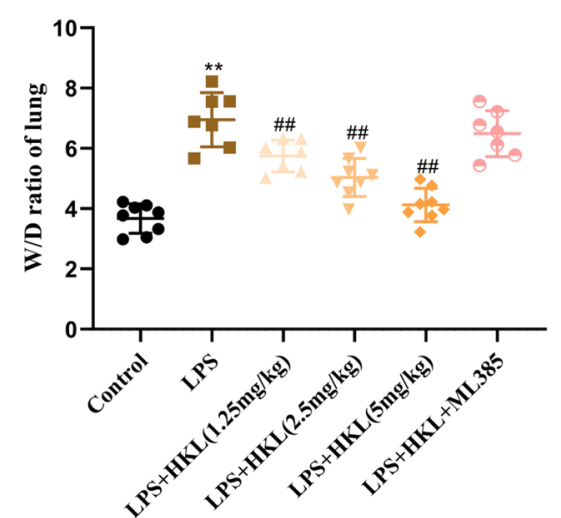

Fig. 6 Honokiol attenuates LPS-induced ALI. The male SD rats were intratracheally instilled with LPS ( $5 \mathrm{mg} / \mathrm{kg})$ to establish the ALI model. Then rats were administrated with $H K L(1.25,2.5,5 \mathrm{mg} / \mathrm{kg})$ or ML385 $(30 \mathrm{mg} / \mathrm{kg})$ intraperitoneally based on the grouped information. Rats were euthanized $24 \mathrm{~h}$ after LPS administration. A Flow diagrams of animal experiments, the rats were divided into six groups: control group, LPS group, LPS + HKL $(1.25,2.5,5 \mathrm{mg} / \mathrm{kg})$ groups, LPS + HKL $(2.5 \mathrm{mg} / \mathrm{kg})+\mathrm{ML} 385(30 \mathrm{mg} / \mathrm{kg})$ group. B Representative images of H\&E staining (original magnification $\times 200$ ). C Lung injury score. $\mathbf{D}$ Lung wet/dry weight ratio. Data were analyzed using one-way ANOVA; $n=7-8$ rats per group. ${ }^{* *} P<0.01$ compared with the control group; ${ }^{*} P<0.05$, ${ }^{\# \#} P<0.01$ compared with LPS group 


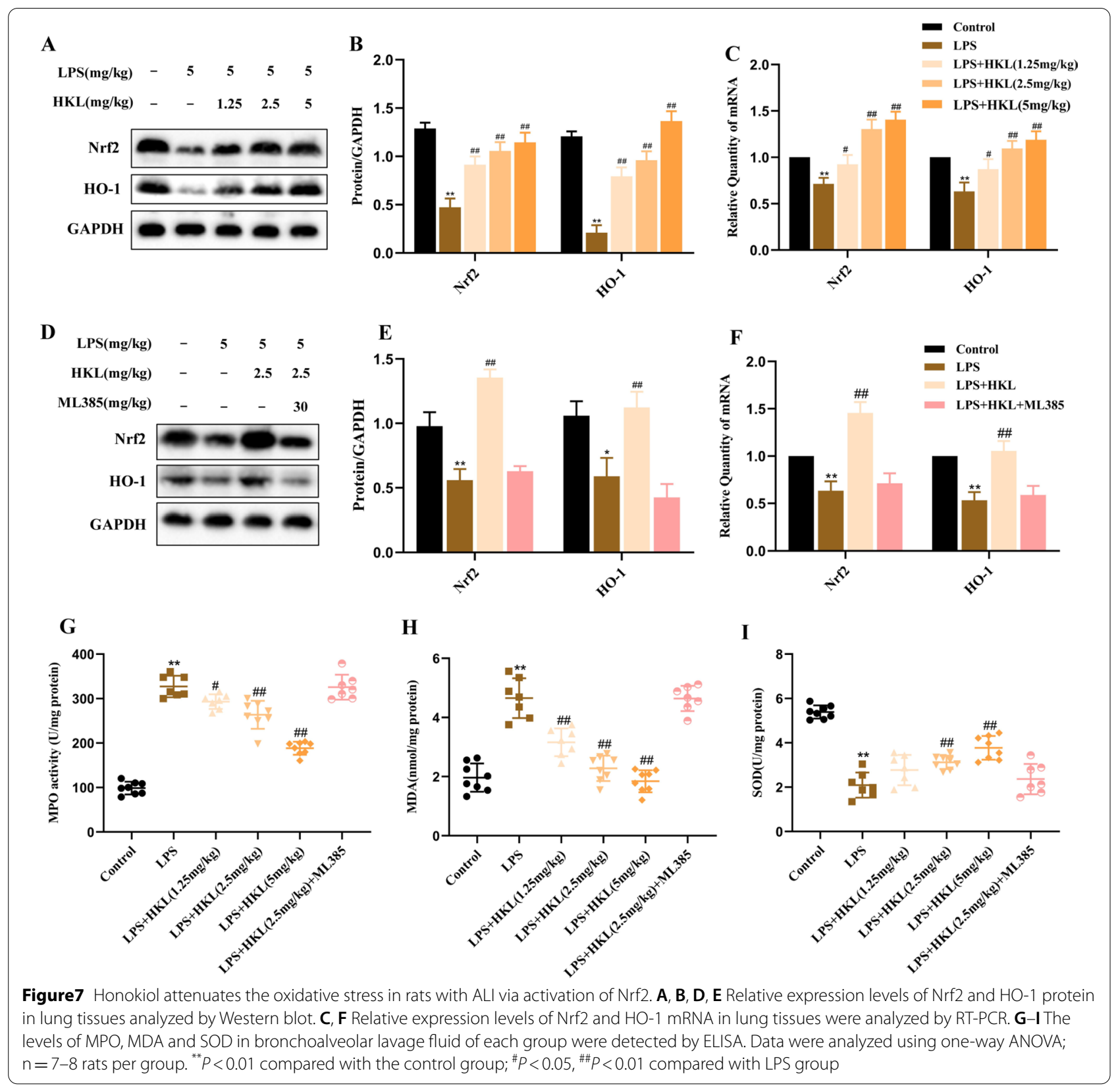

attenuate the LPS-induced ALI via inhibiting the NLRP3 inflammasome-mediated pyroptosis, which was at least partially dependent on the activation of Nrf2.

\section{Discussion}

ALI and ARDS constitute serious respiratory diseases with high morbidity and mortality [27]. However, there

(See figure on next page.)

Fig. 8 Honokiol inhibits NLRP3 inflammasome-mediated pyroptosis in rats with ALI via activation of Nrf2. A-B, D-E Relative expression levels of NLRP3, ASC, CASP1-P20, GSDMD-N protein in lung tissues were analyzed by western blot. C, F Relative expression levels of NLRP3, ASC, CASP1, GSDMD mRNA in lung tissues were analyzed by RT-PCR. G-I The content of IL-18, IL-1 $\beta$ and LDH in bronchoalveolar lavage fluid of each group were detected by ELISA. J Immunohistochemical staining of GSDMD (original magnification $400 \times$ ) in the rat lungs. $\mathbf{K}$ The average optical density (AOD) was used to evaluate the intensity of IHC staining and measured by Image-Pro Plus 6.0 software. Data were analyzed using one-way ANOVA; $n=7-8$ rats per group. ${ }^{* *} P<0.01$ compared with the control group; ${ }^{\prime} P<0.05, \# P<0.01$ compared with LPS group 


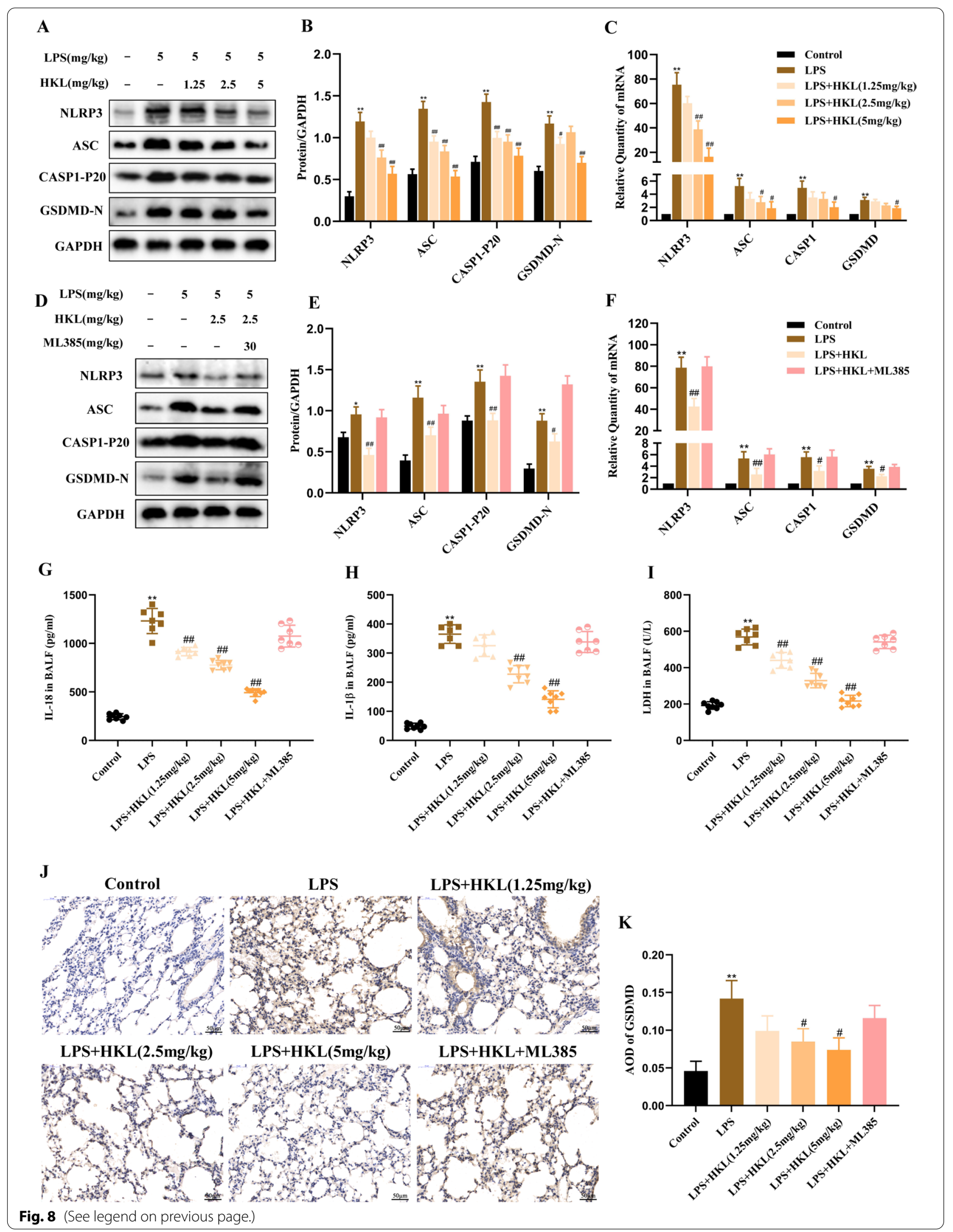


is no specific treatment for ALI to date. With the development of phytochemistry and pharmacology research, a large number of natural products with anti-oxidant, anti-inflammatory and anti-bacterial activities have been found. Therefore, there is an increasing demand for the botanical components of traditional medicine as a source of prevention and treatment for ALI [28-30]. HKL, a natural compound extracted from Magnolia Officinalis, has been reported to have anti-oxidant and anti-inflammatory effects. This study aimed to investigate the therapeutic effects and protective mechanisms of HKL on ALI induced by LPS.

The pathogenesis of ALI is still not conclusively known. Lung barrier damage, lung epithelial injury, inflammation and oxidative damage are the main characteristics of ALI [31-34]. Accumulating pieces of evidence suggest that airway epithelium is involved in the pathogenesis of ALI / ARDS $[35,36]$. The airway epithelium is the body's first line of defense against lung injury [4]. Previous studies have shown that the activation of airway epithelial cells could produce pro-inflammatory factors, which aggravated the development of pulmonary edema in LPS induced-ALI [3]. It has been reported that excessive activation of NLRP3 inflammasome aggravated lung inflammation and tissue damage [37]. Activation of NLRP3 inflammasome could promote the formation of GSDMD pore and the secretion of IL- $1 \beta$, IL- 18 via CASP1 activation, thereby inducing the occurrence of pyroptosis [38-41]. However, the role of NLRP3 inflammasomemediated pyroptosis in airway epithelial cells for ALI has not been studied.

In our study, in vitro, BEAS-2B cells were stimulated with LPS and ATP to induce pyroptosis, and the rate of PI-positive cells, the release of LDH, IL-18, IL-1 $\beta$, and the NLRP3, ASC, CASP1-P20, GSDMD-N protein levels and NLRP3, ASC, CASP1, GSDMD mRNA levels were significantly increased. Meanwhile, HKL was found to reverse the changes of the above indicators. In addition, the antipyroptotic effect of HKL has also been demonstrated in vivo. The rat model of ALI was established by intratracheal instillation of LPS. It was found that HKL could decrease the protein levels of NLRP3, ASC, CASP1-P20, GSDMD-N and mRNA levels of NLRP3, ASC, CASP1, GSDMD in lung tissues, and the content of LDH, IL-18, IL- $1 \beta$ in BALF. The above results suggest that HKL may improve LPS-induced ALI by inhibiting NLRP3 inflammasome-mediated pyroptosis in airway epithelial cells, and also indicate that pyroptosis in airway epithelium may be one of the potential targets for the prevention and treatment of ALI.

Disorders associated with oxidative stress can increase lung inflammation and aggravate the progression of ALI [42, 43]. Nrf2, as a basic leucine zipper redox-sensitive transcription factor, can regulate oxidative stress and inflammation [44, 45]. Activation of Nrf2 can facilitate the expression of HO-1, defending against oxidative stress [46, 47]. Recent research showed that the activation of $\mathrm{Nrf} 2 / \mathrm{HO}-1$ signaling pathway could protect the oxidative stress-related damage in ALI $[48,49]$. As previously mentioned, HKL has strong antioxidant activity, so we hypothesized that HKL could reduce oxidative stress and attenuate LPS-induced ALI via activation of Nrf2/HO-1 signaling pathway. Our results suggested that HKL could significantly upregulate the protein and mRNA expression levels of Nrf2 and HO-1, decrease the levels of MPO, MDA, and enhance the level of SOD in vivo and in vitro. And we also discovered that the anti-oxidant effect of HKL could be reversed by Nrf2 knockdown, which indicated that HKL played an anti-oxidative role in LPS-induced ALI via regulating $\mathrm{Nrf} 2 / \mathrm{HO}-1$ signaling pathway.

The current study also showed that Nrf2 negatively regulated the activation of NLRP3 inflammasome [50, 51]. It has been reported that Nrf2 could inhibit the activation of NLRP3 inflammasome by enhancing Trx activity and suppressing TXNIP in human-derived neuronal cells [52], and Nrf2-antioxidant signaling could inhibit the NLRP3/IL-1 $\beta$ pathway in human corneal epithelial cells [53]. Meanwhile, studies have revealed that Nrf2/HO-1 pathway could suppress NF-kB-p65 phosphorylation to inhibit NLRP3 inflammasome activation in myeloid-derived suppressor cells [54]. In addition, ROS-induced NLRP3 inflammasome activation in BV2 cells was also related to Nrf2 / ARE pathway [55]. However, it is not clear whether Nrf2 can regulate NLRP3 inflammasome activation in BEAS-2B cells. Therefore, we pretreated the cells with TBHQ (an Nrf2 agonist) and observed its effect on NLRP3 inflammasome activation. The results showed that TBHQ could significantly inhibit the activation of NLRP3 inflammasome and reduce the degree of pyroptosis. Our preceding results suggest that HKL activates Nrf2 and inhibits NLRP3 inflammasome-mediated pyroptosis, then, we advanced the conjecture that the inhibitory effect of HKL on NLRP3 inflammasome-mediated pyroptosis may be due to the Nrf2 activation. To verify this conjecture, siRNA was used to silence Nrf2 in vitro and ML385 (an Nrf2 inhibitor) was used to block the activation of Nrf2 in vivo. Interestingly, we found that after the Nrf2 knockdown, the inhibitory effect of HKL on NLRP3 inflammasome-mediated pyroptosis was reversed in vitro and in vivo. These results suggest that HKL may inhibit NLRP3 inflammasome-mediated pyroptosis by activating Nrf2, which plays a protective role in LPS-induced ALI. 


\section{Conclusion}

In this study, we found that HKL could attenuate NLRP3 inflammasome-mediated pyroptosis in BEAS$2 \mathrm{~B}$ cells via activating Nrf2. Meanwhile, we verified that HKL could inhibit NLRP3 inflammasome-mediated pyroptosis by activating Nrf2 to reduce LPS-induced ALI. Overall, these results reveal the new protective mechanism of HKL on ALI, providing an experimental basis for their clinical applications in the future. However, numerous safety and efficacy studies are necessary before its clinical applications. Furthermore, the specific mechanism of the connection between Nrf2 and NLRP3 inflammasome needs to be further explored in future studies.

\section{Abbreviations}

HKL: Honokiol; LPS: Lipopolysaccharide; ALI: Acute lung injury; NLRP3: NODlike receptor family pyrin domain containing 3; ASC: Apoptosis-associated speck-like protein containing a caspase-recruitment domain; CASP1: Caspase-1; GSDMD: Gasdermin D; IL-1ß: Interleukin-1 beta; Nrf2: Nuclear factor erythroid-2 related factor 2; HO-1: Heme oxygenase-1; MPO: Myeloperoxidase; MDA: Malondialdehyde; SOD: Superoxide dismutase; PI: Propidium iodide; BEAS-2B: Human bronchial epithelial cell line; PBS: Phosphate buffer saline; DMEM: Dulbecco's modified Eagle's medium; FBS: Fetal bovine serum; siRNA: Small interfering RNA; BALF: Bronchoalveolar lavage fluid; PMSF: Phenylmethanesulphonyl fluoride; RIPA: RIPA Lysis Buffer; CCK8: Cell counting Kit-8; LDH: Lactate dehydrogenase; i.p.: Intraperitoneal; H\&E: Hematoxylin and eosin
\end{abstract}

\section{Acknowledgements}

The study was performed in Central Laboratory of Union Hospital, Tongji Medical College, Huazhong University of Science and Technology. We would like to acknowledge Sheng Wang, Tao Zhou and Cuiling Liu for their laboratory assistance.

\section{Authors' contributions}

$Y L$ designed and completed the experiment, analyzed data and wrote the manuscript. JZ, YL and LS assisted in animal experiments. JL and FZ participated in data processing and analysis. SY supervised this experiment and reviewed this manuscript. All authors read and approved the final manuscript.

\section{Funding}

This study was supported by the National Natural Science Foundation of China (No. 81673760, No.81874397) and Hubei Provincial Key Research and Development Program (No. 2020BCA065).

\section{Availability of data and materials}

The data analyzed during this study can be obtained from the corresponding author on reasonable request.

\section{Declarations}

\section{Ethics approval and consent to participate}

All experiments were performed according to the Good Animal Practice requirements of the Animal Ethics Procedures and Guidelines of the People's Republic of China, and were approved by the Institutional Animal Care and Use Committee at Tongji Medical College, Huazhong University of Science and Technology (S2428)

\section{Consent for publication}

All authors agree to publish this article.

\section{Competing interests}

The authors declare no conflict of interest.

\section{Author details}

${ }^{1}$ Department of Integrated Traditional Chinese and Western Medicine, Union Hospital, Tongji Medical College, Huazhong University of Science and Technology, Wuhan 430022, China. ${ }^{2}$ Department of Neurosurgery, Union Hospital, Tongji Medical College, Huazhong University of Science and Technology, Wuhan 430022, China. ${ }^{3}$ School of Clinical Medical, Hubei University of Chinese Medicine, Wuhan 430060, China.

Received: 19 September 2021 Accepted: 19 November 2021

Published online: 29 November 2021

\section{References}

1. Butt Y, Kurdowska A, Allen TC. Acute lung injury: a clinical and molecular review. Arch Pathol Lab Med. 2016;140:345-50. https://doi.org/10.5858/ arpa.2015-0519-RA.

2. Ware LB, Matthay MA. The acute respiratory distress syndrome. N Engl J Med. 2000:342:1334-49. https://doi.org/10.1056/nejm200005043421806.

3. Chen H, Bai C, Wang X. The value of the lipopolysaccharide-induced acute lung injury model in respiratory medicine. Expert Rev Respir Med. 2010;4:773-83. https://doi.org/10.1586/ers.10.71.

4. Wang X, Adler KB, Erjefalt J, Bai C. Airway epithelial dysfunction in the development of acute lung injury and acute respiratory distress syndrome. Expert Rev Respir Med. 2007;1:149-55. https://doi.org/10.1586/ 17476348.1.1.149.

5. Shao BZ, Xu ZQ, Han BZ, Su DF, Liu C. NLRP3 inflammasome and its inhibitors: a review. Front Pharmacol. 2015;6:262. https://doi.org/10.3389/fphar. 2015.00262.

6. He Y, Hara H, Núñez G. Mechanism and regulation of NLRP3 inflammasome activation. Trends Biochem Sci. 2016;41:1012-21. https://doi.org/ 10.1016/j.tibs.2016.09.002.

7. Ding J, Wang K, Liu W, She Y, Sun Q, Shi J, Sun H, Wang DC, Shao F. Poreforming activity and structural autoinhibition of the gasdermin family. Nature. 2016;535:111-6. https://doi.org/10.1038/nature18590.

8. Zeng Y, Qin Q, Li K, Li H, Song C, Li Y, Dai M, Lin F, Mao Z, Li Q, et al. PKR suppress NLRP3-pyroptosis pathway in lipopolysaccharide-induced acute lung injury model of mice. Biochem Biophys Res Commun. 2019;519:814. https://doi.org/10.1016/j.bbrc.2019.08.054.

9. Ahmed SM, Luo L, Namani A, Wang XJ, Tang X. Nrf2 signaling pathway: pivotal roles in inflammation. Biochimica et biophysica acta Mol Basis Dis. 2017;1863:585-97. https://doi.org/10.1016/j.bbadis.2016.11.005.

10. Ma Q. Role of nrf2 in oxidative stress and toxicity. Annu Rev Pharmacol Toxicol. 2013;53:401-26. https://doi.org/10.1146/annurev-pharm tox-011112-140320.

11. Tkachev VO, Menshchikova EB, Zenkov NK. Mechanism of the Nrf2/ Keap1/ARE signaling system. Biochemistry Biokhimiia. 2011;76:407-22. https://doi.org/10.1134/s0006297911040031.

12. Hou Y, Wang Y, He Q, Li L, Xie H, Zhao Y, Zhao J. Nrf2 inhibits NLRP3 inflammasome activation through regulating TrX1/TXNIP complex in cerebral ischemia reperfusion injury. Behav Brain Res. 2018;336:32-9. https:// doi.org/10.1016/j.bbr.2017.06.027.

13. Rickert U, Cossais F, Heimke M, Arnold P, Preuße-Prange A, Wilms H, Lucius R. Anti-inflammatory properties of Honokiol in activated primary microglia and astrocytes. J Neuroimmunol. 2018;323:78-86. https://doi.org/10. 1016/j.jneuroim.2018.07.013.

14. Liu JX, Shen SN, Tong Q, Wang YT, Lin LG. Honokiol protects hepatocytes from oxidative injury through mitochondrial deacetylase SIRT3. Eur J Pharmacol. 2018;834:176-87. https://doi.org/10.1016/j.ejphar.2018.07. 036.

15. Zhang B, Zhai M, Li B, Liu Z, Li K, Jiang L, Zhang M, Yi W, Yang J, Yi D, et al. Honokiol ameliorates myocardial ischemia/reperfusion injury in type 1 diabetic rats by reducing oxidative stress and apoptosis through activating the SIRT1-Nrf2 signaling pathway. Oxid Med Cell Longev. 2018;2018:3159801. https://doi.org/10.1155/2018/3159801.

16. Tang P, Gu JM, Xie ZA, Gu Y, Jie ZW, Huang KM, Wang JY, Fan SW, Jiang $X S$, Hu ZJ. Honokiol alleviates the degeneration of intervertebral disc via suppressing the activation of TXNIP-NLRP3 inflammasome signal pathway. Free Radical Biol Med. 2018;120:368-79. https://doi.org/10. 1016/j.freeradbiomed.2018.04.008. 
17. Wang R, Wang Y, Hu L, Lu Z, Wang X. Inhibition of complement C5a receptor protects lung cells and tissues against lipopolysaccharideinduced injury via blocking pyroptosis. Aging. 2021;13:8588-98. https://doi.org/10.18632/aging.202671.

18. Chen C, Jiang X, Gu S, Lai Y, Liu Y, Zhang Z. Protection of Nrf2 against arsenite-induced oxidative damage is regulated by the cyclic guanosine monophosphate-protein kinase $\mathrm{G}$ signaling pathway. Environ Toxicol. 2017;32:2004-20. https://doi.org/10.1002/tox.22374.

19. Baffour Tonto P, Yasuma T, Kobayashi T, D'Alessandro-Gabazza CN, Toda M, Saiki H, Fujimoto H, Asayama K, Fujiwara K, Nishihama K, et al. Protein $S$ is protective in acute lung injury by inhibiting cell apoptosis. Int J Mol Sci. 2019. https://doi.org/10.3390/ijms20051082.

20. Weng TI, Wu HY, Kuo CW, Liu SH. Honokiol rescues sepsis-associated acute lung injury and lethality via the inhibition of oxidative stress and inflammation. Intensive Care Med. 2011;37:533-41. https://doi.org/10. 1007/s00134-010-2104-1.

21. Feng LX, Zhao F, Liu Q, Peng JC, Duan XJ, Yan P, Wu X, Wang HS, Deng $\mathrm{YH}$, Duan SB. Role of Nrf2 in lipopolysaccharide-induced acute kidney injury: protection by human umbilical cord blood mononuclear cells. Oxid Med Cell Longev. 2020;2020:6123459. https://doi.org/10.1155/ 2020/6123459.

22. Matute-Bello G, Downey G, Moore BB, Groshong SD, Matthay MA, Slutsky AS, Kuebler WM. An official American Thoracic Society workshop report: features and measurements of experimental acute lung injury in animals. Am J Respir Cell Mol Biol. 2011;44:725-38. https://doi.org/ 10.1165/rcmb.2009-0210ST.

23. Huang M, Zeng S, Zou Y, Shi M, Qiu Q, Xiao Y, Chen G, Yang X, Liang L, $\mathrm{Xu} \mathrm{H}$. The suppression of bromodomain and extra-terminal domain inhibits vascular inflammation by blocking NF-KB and MAPK activation. Br J Pharmacol. 2017;174:101-15. https://doi.org/10.1111/bph.13657.

24. Hou Y, Peng S, Li X, Yao J, Xu J, Fang J. Honokiol alleviates oxidative stress-induced neurotoxicity via activation of Nrf2. ACS Chem Neurosci. 2018;9:3108-16. https://doi.org/10.1021/acschemneuro.8b00290.

25. Tonelli C, Chio IIC, Tuveson DA. Transcriptional regulation by Nrf2. Antioxid Redox Signal. 2018;29:1727-45. https://doi.org/10.1089/ars. 2017.7342.

26. Yan Z, Qi W, Zhan J, Lin Z, Lin J, Xue X, Pan X, Zhou Y. Activating Nrf2 signalling alleviates osteoarthritis development by inhibiting inflammasome activation. J Cell Mol Med. 2020;24:13046-57. https://doi.org/ 10.1111/jcmm.15905

27. Thompson BT, Chambers RC, Liu KD. Acute respiratory distress syndrome. N Engl J Med. 2017;377:562-72. https://doi.org/10.1056/NEJMr a1608077.

28. Alzohairy MA, Khan AA, Alsahli MA, Almatroodi SA, Rahmani AH. Protective effects of thymoquinone, an active compound of nigella sativa, on rats with Benzo(a)pyrene-Induced Lung injury through regulation of oxidative stress and inflammation. Molecules (Basel, Switzerland). 2021. https://doi.org/10.3390/molecules26113218.

29. Mahalanobish S, Saha S, Dutta S, Sil PC. Mangiferin alleviates arsenic induced oxidative lung injury via upregulation of the $\mathrm{Nrf2}-\mathrm{HO} 1$ axis Food and Chem Toxicol Int J Publ Br Ind Biol Res Assoc. 2019;126:41-55. https://doi.org/10.1016/j.fct.2019.02.022.

30. Dong ZW, Yuan YF. Juglanin suppresses fibrosis and inflammation response caused by LPS in acute lung injury. Int J Mol Med. 2018:41:3353-65. https://doi.org/10.3892/ijmm.2018.3554.

31. Kosutova P, Mikolka P, Kolomaznik M, Balentova S, Adamkov M, Calkovska A, Mokra D. Reduction of lung inflammation, oxidative stress and apoptosis by the PDE4 inhibitor roflumilast in experimental model of acute lung injury. Physiol Res. 2018;67:S645-s654. https://doi.org/10.33549/physi olres.934047.

32. Sim TY, Harith HH, Tham CL, Md Hashim NF, Shaari K, Sulaiman MR, Israf $D A$. The protective effects of a synthetic geranyl acetophenone in a cellular model of TNF-a-induced pulmonary epithelial barrier dysfunction. Molecules (Basel, Switzerland). 2018. https://doi.org/10.3390/molecules2 3061355.

33. Herold S, Gabrielli NM, Vadász I. Novel concepts of acute lung injury and alveolar-capillary barrier dysfunction. Am J Physiol Lung Cell Mol Physiol. 2013;305:L665-681. https://doi.org/10.1152/ajplung.00232.2013.
34. Manicone AM. Role of the pulmonary epithelium and inflammatory signals in acute lung injury. Expert Rev Clin Immunol. 2009;5:63-75. https:// doi.org/10.1586/177666x.5.1.63.

35. Wittekindt $\mathrm{OH}$. Tight junctions in pulmonary epithelia during lung inflammation. Pflugers Arch. 2017;469:135-47. https://doi.org/10.1007/ s00424-016-1917-3.

36. Brune K, Frank J, Schwingshackl A, Finigan J, Sidhaye VK. Pulmonary epithelial barrier function: some new players and mechanisms. Am J Physiol Lung Cell Mol Physiol. 2015;308:L731-745. https://doi.org/10.1152/ajplu ng.00309.2014.

37. Zhang Y, Li X, Grailer JJ, Wang N, Wang M, Yao J, Zhong R, Gao GF, Ward PA, Tan DX, et al. Melatonin alleviates acute lung injury through inhibiting the NLRP3 inflammasome. J Pineal Res. 2016;60:405-14. https://doi.org/ 10.1111/jpi.12322.

38. Sharma D, Kanneganti TD. The cell biology of inflammasomes: mechanisms of inflammasome activation and regulation. J Cell Biol. 2016;213:617-29. https://doi.org/10.1083/jcb.201602089.

39. Wang L, Hauenstein AV. The NLRP3 inflammasome: mechanism of action, role in disease and therapies. Mol Aspects Med. 2020;76: 100889. https:// doi.org/10.1016/j.mam.2020.100889.

40. Shi J, Zhao Y, Wang K, Shi X, Wang Y, Huang H, Zhuang Y, Cai T, Wang F, Shao F. Cleavage of GSDMD by inflammatory caspases determines pyroptotic cell death. Nature. 2015;526:660-5. https://doi.org/10.1038/ nature15514.

41. Liu X, Zhang Z, Ruan J, Pan Y, Magupalli VG, Wu H, Lieberman J. Inflammasome-activated gasdermin $D$ causes pyroptosis by forming membrane pores. Nature. 2016;535:153-8. https://doi.org/10.1038/nature18629.

42. Xia W, Pan Z, Zhang H, Zhou Q, Liu Y. Inhibition of ERRa aggravates sepsis-induced acute lung injury in rats via provoking inflammation and oxidative stress. Oxid Med Cell Longev. 2020;2020:2048632. https://doi. org/10.1155/2020/2048632.

43. Gong Y, Yu Z, Gao Y, Deng L, Wang M, Chen Y, Li J, Cheng B. FABP4 inhibitors suppress inflammation and oxidative stress in murine and cell models of acute lung injury. Biochem Biophys Res Commun. 2018;496:111521. https://doi.org/10.1016/j.bbrc.2018.01.150.

44. Nguyen T, Nioi P, Pickett CB. The Nrf2-antioxidant response element signaling pathway and its activation by oxidative stress. J Biol Chem. 2009;284:13291-5. https://doi.org/10.1074/jbc.R900010200.

45. Kuhn AM, Tzieply N, Schmidt MV, von Knethen A, Namgaladze D, Yamamoto M, Brüne B. Antioxidant signaling via Nrf2 counteracts lipopolysaccharide-mediated inflammatory responses in foam cell macrophages. Free Radical Biol Med. 2011;50:1382-91. https://doi.org/10.1016/j.freer adbiomed.2011.02.036.

46. Luo X, Xiao L, Yang H, Zhang R, Jiang M, Ni J, Lei T, Wang N. Homocysteine downregulates gene expression of heme oxygenase-1 in hepatocytes. Nutr Metab. 2014;11:55. https://doi.org/10.1186/1743-7075-11-55.

47. Alam J, Stewart D, Touchard C, Boinapally S, Choi AM, Cook JL. Nrf2, a Cap'n'Collar transcription factor, regulates induction of the heme oxygenase-1 gene. J Biol Chem. 1999;274:26071-8. https://doi.org/10.1074/jbc. 274.37.26071.

48. Zhou J, Chen F, Yan A, Xia X. Madecassoside protects retinal pigment epithelial cells against hydrogen peroxide-induced oxidative stress and apoptosis through the activation of Nrf2/HO-1 pathway. 2020. Biosci Rep. https://doi.org/10.1042/bsr20194347.

49. Du Y, You L, Ni B, Sai N, Wang W, Sun M, Xu R, Yao Y, Zhang Z, Qu C, et al. Phillyrin mitigates apoptosis and oxidative stress in hydrogen peroxidetreated RPE cells through activation of the Nrf2 signaling pathway. Oxid Med Cell Longev. 2020;2020:2684672. https://doi.org/10.1155/2020/ 2684672.

50. Chen Z, Zhong H, Wei J, Lin S, Zong Z, Gong F, Huang X, Sun J, Li P, Lin H, et al. Inhibition of $\mathrm{Nrf} 2 / \mathrm{HO}-1$ signaling leads to increased activation of the NLRP3 inflammasome in osteoarthritis. Arthritis Res Ther. 2019;21:300. https://doi.org/10.1186/s13075-019-2085-6.

51. Zeng J, Chen Y, Ding R, Feng L, Fu Z, Yang S, Deng X, Xie Z, Zheng S. Isoliquiritigenin alleviates early brain injury after experimental intracerebral hemorrhage via suppressing ROS- and/or NF-KB-mediated NLRP3 inflammasome activation by promoting Nrf2 antioxidant pathway. J Neuroinflammation. 2017;14:119. https://doi.org/10.1186/s12974-017-0895-5. 
52. Wang $C Y, X u$ Y, Wang $X$, Guo C, Wang T, Wang ZY. DI-3-n-butylphthalide inhibits NLRP3 inflammasome and mitigates alzheimer's-like pathology via Nrf2-TXNIP-TrX axis. Antioxid Redox Signal. 2019;30:1411-31. https:// doi.org/10.1089/ars.2017.7440.

53. Dai Y, Zhang J, Xiang J, Li Y, Wu D, Xu J. Calcitriol inhibits ROS-NLRP3-IL-1 $\beta$ signaling axis via activation of Nrf2-antioxidant signaling in hyperosmotic stress stimulated human corneal epithelial cells. Redox Biol. 2019;21: 101093. https://doi.org/10.1016/j.redox.2018.101093.

54. Li D, Shi G, Wang J, Zhang D, Pan Y, Dou H, Hou Y. Baicalein ameliorates pristane-induced lupus nephritis via activating $\mathrm{Nrf2/HO}-1$ in myeloidderived suppressor cells. Arthritis Res Ther. 2019;21:105. https://doi.org/ 10.1186/s13075-019-1876-0.
55. Xu X, Zhang L, Ye X, Hao Q, Zhang T, Cui G, Yu M. Nrf2/ARE pathway inhibits ROS-induced NLRP3 inflammasome activation in BV2 cells after cerebral ischemia reperfusion. Inflamm Res. 2018;67:57-65. https://doi. org/10.1007/s00011-017-1095-6.

\section{Publisher's Note}

Springer Nature remains neutral with regard to jurisdictional claims in published maps and institutional affiliations.
Ready to submit your research? Choose BMC and benefit from:

- fast, convenient online submission

- thorough peer review by experienced researchers in your field

- rapid publication on acceptance

- support for research data, including large and complex data types

- gold Open Access which fosters wider collaboration and increased citations

- maximum visibility for your research: over $100 \mathrm{M}$ website views per year

At BMC, research is always in progress.

Learn more biomedcentral.com/submissions 